\title{
A Power-Challenging Theory of Society, or a Conservative Mindset? Upward and Downward Conspiracy Theories as Ideologically Distinct Beliefs
}

\author{
Kenzo Nera ${ }^{1,2}$, Pascal Wagner-Egger ${ }^{3}$, Paul Bertin $^{4}$, Karen M. Douglas ${ }^{5}$, \& Olivier Klein ${ }^{1}$ \\ ${ }^{1}$ Center for Social and Cultural Psychology, Université Libre de Bruxelles (Belgium) \\ ${ }^{2}$ Fonds de la Recherche Scientifique (Belgium) \\ ${ }^{3}$ Département de Psychologie, Université de Fribourg (Switzerland) \\ ${ }^{4}$ LAPCOS, Université Côte d'Azur, Nice (France) \\ ${ }^{5}$ School of Psychology, University of Kent, Canterbury (United Kingdom)
}

\begin{abstract}
Author Note
None of the authors have any conflict of interest to declare. They moreover confirm that this article adheres to ethical guidelines specified in the APA Code of Conduct as well as the national ethics guidelines of Belgium. With the consent of the participants, all data and analyses reported in the manuscript have been uploaded on a dedicated page on the Open Science Framework: https://osf.io/utvf3/

Correspondence concerning this article should be addressed to Kenzo Nera, Université Libre de Bruxelles CP 122, 1050 Bruxelles, Belgium. E-mail: kenzo.nera@ulb.be
\end{abstract}




\begin{abstract}
Even though conspiracy theories are diverse, they are typically construed as a homogeneous phenomenon. Based on classic theorizations of conspiracy theories by Popper (1945; 2002) and Moscovici (1987), we propose to distinguish between belief in upward conspiracy theories (i.e., targeting relatively powerful groups) and downward conspiracy theories (i.e., targeting relatively powerless groups). The former are theorized as powerchallenging beliefs and the latter are theorized as being underpinned by conservative ideology. Across three studies conducted in Belgium (Total $N=2363$ ), we show that these two types of conspiracy beliefs indeed relate differently to power-challenging attitudes (i.e., political extremism, feelings of leadership breakdown) and conservative ideology. Specifically, upward conspiracy beliefs were characterized by a U-shaped relationship with political orientation (i.e., an "extremism" bias), and a strong relationship with feelings of leadership breakdown. By contrast, downward conspiracy beliefs were strongly associated with conservative ideology. Both types of conspiracy beliefs were, however, positively correlated.
\end{abstract}

Keywords: conspiracy theories, ideology, Popper, Moscovici, conspiracy mindset, power, conservatism

Word count: 10832 


\section{A Power Challenging Theory of Society, or a Conservative Mindset? Upward and Downward Conspiracy Theories as Ideologically Distinct Beliefs}

Conspiracy theories (CTs) can be defined as beliefs that evil groups secretly plot to achieve nefarious goals (Zonis \& Joseph, 1994). CTs blame a variety of groups, such as powerful economic groups (e.g., banks or pharmaceutical companies, van Prooijen et al., 2015), scientific communities (e.g., climate or vaccine scientists, Hornsey \& Fielding, 2018), governments and intelligence services (Brotherton et al., 2013), ethnic or religious groups (e.g., Jews, Kofta \& Sedek, 2005; Muslims, Uenal, 2016), or ideological groups (e.g., gender activists, Marchlewska et al., 2019). Nevertheless, CTs are typically construed as a homogeneous phenomenon, and belief in CTs is often conceptualized as a "mindset", or a stable, individual propensity to believe that conspiracies occur (e.g., Brotherton et al., 2013; Bruder et al., 2013; Imhoff \& Bruder, 2014; Lantian, 2016; but see Sutton \& Douglas, 2020). In the current research, we add nuance to this claim and argue that many CTs can be distinguished as upward (i.e., implicating relatively powerful groups such as bankers, governments, or industrial groups), and downward (i.e., implicating relatively powerless groups such as Muslims, migrants, or LGBT people). We examine the predictors of these different types of conspiracy beliefs, arguing that belief in upward CTs will be predicted by power-challenging beliefs, whereas belief in downward CTs will be predicted by conservative ideology.

\section{The "Single Construct" Approach of Conspiracy Theories and its Limitations}

In one of the first quantitative investigations of conspiracy beliefs, Goertzel (1994) observed that beliefs in (apparently) unrelated CTs were positively correlated. This finding has been replicated numerous times (e.g., Brotherton et al., 2013; Goertzel, 1994; Imhoff \& Bruder, 2014; Lukic et al., 2019; Swami et al., 2011; Wagner-Egger \& Bangerter, 2007; Wood et al., 2012), to the point that it has been identified as the most robust finding in all 
research on CTs (Sutton \& Douglas, 2014). To account for this finding, authors have suggested the existence of a generic belief system underpinning the endorsement of CTs, which has been given names such as monological belief system (Goertzel, 1994), generic conspiracist beliefs (Brotherton et al., 2013), or conspiracy mentality (Bruder et al., 2013; Imhoff \& Bruder, 2014; Moscovici, 1987). Social scientists typically construe belief in CTs as a relatively homogeneous phenomenon which can be captured by measures of a “conspiracist mindset” (Swami et al., 2017; Douglas et al., 2019).

However, like any generic approach to a multifaceted phenomenon, this approach has limitations (Sutton \& Douglas, 2014; 2020). First, it tends to conceal the diversity of beliefs labelled as "conspiracy theories" (Harambam \& Aupers, 2016). Second, it implicitly assumes that the endorsement of any CT operates via similar mechanisms (e.g., Douglas et al., 2017; van Prooijen, 2019). As a result, research testing the proposal that the endorsement of different types of CTs might be driven by distinct mechanisms is scarce (see however Sternisko et al., 2020, for an insightful need-based approach that outlines a distinction between different types of CTs, underpinned by distinct psychological motives).

Last, another important limitation of the "single construct" approach to CTs is that there seems to be a variety of conceptualizations of its core component, namely, the “conspiracist mindset" (see Douglas et al., 2019 for a review). It is often simply defined as an individual predisposition to believe in CTs. However, such a definition has little explanatory power, and potentially leads to circular reasoning. Indeed, the main argument for the existence of a "conspiracist mindset" is the observation that individuals who endorse one CT tend to endorse others. Thus, if one endorses the aforementioned definition, explaining that a person believes in a CT because he/she has a general tendency to believe in CTs may not be a substantial theoretical contribution (see Sutton \& Douglas, 2020 for other critiques of the conspiracy mindset). Thus, up to now, the "conspiracy mindset" appears more as a robust 
empirical finding, that is usually interpreted as an underlying trait, than an explanatory variable.

In contrast to the "single construct" approach to CTs, some authors have proposed a distinction between CTs involving authorities and CTs primarily involving stigmatized cultural or religious groups (e.g., Campion-Vincent, 2005; Dyrendal et al., 2018; Oliver \& Wood, 2014; Wagner-Egger \& Bangerter, 2007). In this regard, it is interesting to note that throughout history, cultural minorities and foreigners have been the target of numerous accusations of conspiracy (Campion-Vincent, 2005; Moscovici, 1987). In comparison, CTs accusing "enemies from within" (e.g., government, intelligence agencies) seem to be a relatively recent phenomenon, whose origin can be traced back to the French Revolution (Campion-Vincent, 2005). Inspired by this research, we propose that CTs can be conceptualized as upward or downward depending on the alleged conspirator.

\section{Upward and Downward Conspiracy Theories}

We propose that upward CTs implicate relatively powerful groups (e.g., bankers, governments, pharmaceutical companies) and that downward CTs implicate relatively powerless social groups (e.g., Muslims, migrants, LGBT+ people). Since CTs are intrinsically related to a subjective perception of power (e.g., Brotherton, 2014; Moscovici, 1987; Imhoff \& Lamberty, 2020), we propose to primarily anchor this distinction not in perceived power, but in objective power asymmetries within society. Following the definition of social power as "asymmetric control over valued resources in social relations" (Magee \& Galinsky, 2008, p. 361), we propose that downward CTs implicate groups (or associations who represent these groups such as lobbies or NGOs) whose access to these valued resources is restricted - notably because of discrimination. As for upward CTs, they implicate groups who have privileged access to these resources. As we will see, distinguishing CTs based on 
objective rather than subjective power enables us to develop a more fine-grained reflection on how objective and subjective power are articulated with regards to CTs.

This distinction emphasizes the differences between two diverging theoretical approaches to belief in CTs: the conspiracy theory of society (Popper, 1945; 2002) and the conspiracy mentality (Moscovici, 1987, 2020). Both approaches propose that accusations of conspiracy are underpinned by a generic belief system. They further agree that conspiracy believers perceive the alleged conspirators not as a collection of individuals, but as monolithic entities, and that they overly rely on intentional interpretation of social events. However, Popper initiated the idea that CTs primarily target relatively powerful groups, whereas Moscovici initiated an approach centered on individuals' desire to preserve their ingroup against threatening outgroups (and notably, discriminated minorities). In contrast to Popper therefore, Moscovici argued that alleged conspirators need not be powerful.

\section{The Conspiracy Theory of Society and Upward Conspiracy Theories}

In 1962, Popper (2002) described the conspiracy theory of society as the belief that social problems (e.g., economic depressions, wars, shortages) are intentionally perpetuated by powerful groups who benefit from these problems. This idea is rooted in his earlier criticism of what he pejoratively called the "vulgar Marxists" (Popper, 1945, p. 93). According to "vulgar Marxists", Popper says, "Marxism lays bare the sinister secrets of social life by revealing the hidden motives $[\ldots]$ which actuate the powers behind the scenes of history, powers that cunningly and consciously create war, depression, unemployment [...]." (p. 93). We might note that in reality, no group has enough power to entirely control the course of complex social events (Bale, 2007; Keeley, 1999; Popper, 1966). Thus, on the psychological level, upward CTs appear to be about attributing even more power to powerful groups than they actually have. 
This view has significantly influenced social psychological scholarship on CTs. For example, in a recent interdisciplinary review of literature, Douglas et al. (2019) proposed to define CTs as "attempts to explain the ultimate causes of significant social and political events and circumstances with claims of secret plots by two or more powerful actors" (p. 4). Directly inspired by Popper's work, Imhoff and Bruder (2014) have described "conspiracy mentality" as a generalized political attitude that challenges power structures by blaming negative events on powerful groups acting in secret ${ }^{1}$. This political attitude is associated with prejudice against powerful groups (e.g., bankers, Americans, Jews) but not prejudice against powerless groups (e.g., Muslims or Gypsies). Imhoff and Lamberty (2020) further proposed that CTs are intrinsically related to feelings of relative powerlessness (that is, compared to the conspirators' power).

This perspective therefore proposes that CTs are power-challenging phenomena. This view has been supported by research showing that CTs are endorsed to a greater extent by people on the losing side of power asymmetries (Uscinski \& Parent, 2014). For example, after an election, the losing side typically accuses the winning side of cheating (Uscinski \& Parent, 2014; Uscinski et al., 2016) - a finding spectacularly instantiated in the 2020 US elections. Moreover, many CTs are typically endorsed by members of disadvantaged groups, such as disadvantaged ethnic or cultural minorities (Abalakina-Paap et al., 1999; Crocker et al., 1999; Freeman \& Bentall, 2017; Goertzel, 1994; Uscinski \& Parent, 2014; van Prooijen, 2016; van Prooijen, Staman, \& Krouwel, 2018), people experiencing economic insecurity (Freeman \& Bentall, 2017), or people with lower educational attainment (Douglas et al., 2016; Goertzel, 1994; Uscinski \& Parent, 2014; van Prooijen, 2016). This view also finds support in research showing that beliefs in CTs is associated with willingness to engage in

\footnotetext{
${ }^{1}$ Note that this definition of the conspiracy mentality differs from its original conceptualization by Moscovici (1987) developed in the next section.
} 
violent collective action (Imhoff, Dierterle, \& Lamberty, 2020; Jolley \& Paterson, 2020), and political extremism (van Prooijen et al., 2015; Krouwel et al., 2017; Imhoff et al., 2020). Regarding the latter, it is worth noting that according to Popper (2002), far left and far right totalitarian regimes are founded on conspiratorial thinking.

\section{The Conspiracy Mentality and Downward Conspiracy Theories}

Despite some similarities, Moscovici's (1987) understanding of what he was the first to name the "conspiracy mentality" differs from Popper's view. According to Moscovici, CTs are rooted in the threat that minorities (whether religious, ethnic, or political) pose to the majority's most paramount norms, beliefs, and values. Importantly, in his view minorities need not hold actual power (nor, of course, to be actually conspiring) to be accused of conspiring against the majority. Rather, the conspiracy mentality projects power and malevolence on minorities that threaten the majority, even when these minorities are objectively powerless (e.g., immigrants). Thus, downward CTs can be characterized by an attribution of power to objectively powerless groups.

This account differs from Popper's view on key aspects. First and foremost, the power asymmetry between the conspirators (a minority) and the victims of the conspiracy (the majority) is opposite to the one postulated by the conspiracy theory of society. Specifically, in Moscovici's view a CT is typically (but not necessarily) a belief held by the powerful against the powerless. Second, and relatedly, CTs do not aim to challenge power structures, but at something rather the opposite. Specifically, CTs challenge the preservation of the ingroup's norms, values, and beliefs. In other words, CTs are underpinned by conservative concerns.

Moscovici’s perspective also finds support in the empirical literature on CTs. Indeed, many authors have reported that beliefs in CTs are associated with a conservative ideology (Dieguez et al., 2015; Featherstone et al., 2019; Galliford \& Furnham, 2017; Hart \& Graether, 
2018; Imhoff \& Bruder, 2014; Miller et al. 2016; Ståhl \& van Prooijen, 2018; van der Linden, 2015; van der Linden et al., 2020; Wagner-Egger \& Bangerter, 2007; however, for an example of "left-wing bias", see Krouwel et al., 2017). Unsurprisingly, this view garners particularly strong support in research pertaining to CTs targeting stigmatized groups - which were the main concern of Moscovici's reflection on the conspiracy mentality. For example, CTs blaming migrants (Jolley et al., 2019), Muslims (Dyrendal et al., 2018; Swami et al., 2017; Uenal, 2016), gender activists (Marchlewska et al., 2019), Jews (Bilewicz et al., 2013; Dyrendal et al., 2018; Greszniak-Feldman \& Irzycka, 2009; Kofta \& Sedek, 2005), or Black Americans (Miller et al., 2016; Richey, 2017; Pasek et al., 2015) are all strongly related to a conservative ideology. Furthermore, CTs targeting cultural minorities seems to be related to conspiracy stereotypes towards cultural minorities (Kofta \& Sedek, 2005; Uenal, 2016), feelings of symbolic and realistic intergroup threat (Uenal, 2016), and willingness to discriminate against the allegedly conspiring outgroups (Bilewicz et al., 2013). Thus, many disadvantaged groups seem to be targeted by conspiracy beliefs; These examples largely follow our conceptualization of downward CTs and mitigate the idea that CTs necessarily target powerful groups. Note that Jews appear as an exception, as this group suffers from discrimination but is also characterized by high economic and social achievements in many countries (e.g., Mendelssohn, 2015; Muller, 2011). Thus, this group appears to be ambiguous with regards to the distinction between upward and downward CTs. It might be the subject of upward CTs or downward CTs, depending on the context.

\section{Overview of the Research}

The distinction between upward and downward CTs is rooted in the existence of two trends of research in the study of CTs. One construes CTs as resulting from a powerchallenging belief system. The second construes CTs as the expression of conservative concerns regarding the preservation of one's ingroup. In the current research, we examined 
the extent to which belief in upward and downward CTs relate differently to power challenging and conservative attitudes.

Belief in upward and downward CTs were measured through inventories of conspiracy beliefs targeting, respectively, relatively powerful groups (e.g., banks, governments, pharmaceutical companies) or relatively powerless groups (e.g., Muslims, immigrants, LGBT+ people, feminists). Power-challenging attitudes were measured through political extremism (Studies 1-3) and feelings of leadership breakdown (Studies 2-3). Note that political extremism should not be considered a power challenging attitude in every context. However, the far right is virtually non-existent in the political arena of French speaking Belgium (RTBF, 2019) - probably in part because French speaking Belgian media have an agreement never to invite representatives of the far right (de Jonge, 2020). As for the far left, despite its relative success, the PTB (Belgian Workers' Party), "only" came in fourth at the last federal elections (RTBF, 2019). More generally, Belgium has a proportional representation system dominated by both center-to-moderate right and center-to-moderate left; in such a system, extreme policies are less likely to be adopted given that reaching a simple majority demands to assemble a broad coalition (Amy, 2000). For these reasons, we consider that in the French speaking Belgian context, both far left and far right political extremism can be considered as a power-challenging attitude (this would not be the case in a country ruled by a radical right or left party). Finally, conservative attitudes were assessed using two measures of conservatism, namely, the left/right scale, and the social and economic dimensions of conservatism.

Across all studies, we hypothesized that belief in upward CTs and downward CTs would relate significantly differently to conservative and power challenging attitudes. Specifically, we expected belief in upward CTs to be more associated with power challenging attitudes than downward CTs, and belief in downward CTs to be more associated with 
conservative attitudes than upward CTs. Studies 2-3 also provided an opportunity to examine how upward and downward conspiracy beliefs are related to a measure of the conspiracist mindset, namely, the single item conspiracist beliefs scale (Lantian et al., 2016).

Note that the results reported do not follow the pre-registered hypotheses. This is because the current article went through multiple revisions and rewritings and the content of the analyses evolved as a result of this process. We still report results in the form of confirmatory hypotheses for the sake of readability.

\section{Study 1}

All materials, raw data, and analyses scripts for all studies can be accessed at the following address: https://osf.io/utvf3/

In Study 1, we measured conservative attitudes using the left-right scale, as it is one of the most convenient and commonly used measurement of conservatism (Bauer et al., 2017; Everett, 2013). Given the limitations of the left-right scale (Bauer et al., 2017), we also included measures of the economic and social components of conservatism (Everett, 2013) to examine how these subcomponents relate to both types of conspiracy beliefs.

To measure power challenging attitudes, we also relied on the left-right scale, as it also enables to measure political extremism. Indeed, a U-shaped relation between political orientation and a given variable shows that this variable is more prevalent at the political extremes. To capture such a U-shaped relation, we relied on quadratic regressions, as well as the two lines test proposed by Simonsohn (2018).

We first hypothesized that upward and downward CTs would have a significantly different relation with conservatism, as captured by the left-right scale (H1). Specifically, we expected downward CTs to be positively associated with a right-wing political orientation (H2), more than upward CTs. We expected the same pattern for the dimensions of 
conservatism (H3-4). Regarding power challenging attitudes, we expected beliefs in upward and downward CTs to have significantly different relations with political extremism (H5). Last, we hypothesized that upward CTs would have a U-shaped relation with political orientation (H6).

\section{Method}

\section{Participants}

Nine hundred and sixty two Belgian residents completed the online questionnaire, out of which 786 remained (326 women, 460 men; $M_{\text {age }}=54.5$ years old, ranging from 18 to 90, $S D=15.8$ years) after excluding those who did not answer the attention check ("Please tick box 7”), or seriousness check (“did you answer honestly to this questionnaire, took the time to read the questions, without being distracted?" Y/N) correctly, or were under 18 years old. Students were $6.5 \%$ of the sample $(N=48), 30.1 \%$ were employees $(N=238), 7.8 \%$ were self-employed $(N=62), 40.8 \%$ were retired $(N=322$, this overrepresentation is addressed in Studies 2 and 3), 4.4\% were unemployed $(N=34)$, and the remaining $10.4 \%(N=82)$ ticked the box "other". The mean for political orientation was $5.16(1=$ far left, $11=$ far right; $S D=$ 2.43). For a given power of .90 , the sample size enabled us to detect an effect size of $r=.11$ with two tailed tests.

\section{Materials and Procedure}

Our questionnaire was uploaded on the LimeSurvey platform. Participants were recruited in October 2017 using a sponsored advertisement on Facebook. The study was presented as "A study about Belgian society". On the first page of the questionnaire, participants read a short text thanking them for their participation. They were informed that by continuing, they gave their consent to participate in the study and that an anonymized version of the data would be uploaded on an open-access platform for other researchers. The scales were completed in the following order: social and economic conservatism scale, 
conspiracy beliefs scale, perceived intergroup symbolic and realistic threat, and sociodemographic questions.

Upward $(\alpha=.84)$ and Downward $(r=.40)$ Conspiracy Beliefs. Five items referred to CTs involving powerful groups (e.g., "the press is secretly controlled by the elites to manufacture consent about the status quo while giving the illusion of democratic debate"; "Some pharmaceutical groups encourage the spreading of diseases because they have the monopoly on the treatments"). Two items measured the endorsement of CTs involving relatively powerless groups, namely, Muslims and LGBTI+ people (see European Union Agency for Fundamental Rights, 2012; Unia, 2019; for data regarding, respectively, the discrimination experienced by LGBT+ people and immigrants in Belgium): "Some Muslim organizations [...] are secretly plotting to impose Islam in Europe"; "The LGBTI lobby pretends to be promoting equality, but its actual goal is $[\ldots]$ to destroy traditional family norms." Participants answered to those items on a scale ranging from 1 (totally disagree) to 10 (totally agree). Confirmatory factor analyses using the R package "lavaan" (Rosseel et al., 2019) suggested that the two-factor structure fitted the data, Chisq/df $=6.23, \mathrm{p}<.001, \mathrm{CFI}=$ $.97, \mathrm{TLI}=.95, \mathrm{RMSEA}=.08, \mathrm{SRMR}=0.03$, significantly better than a single-factor structure Chisq $/ \mathrm{df}=10.52, \mathrm{CFI}=.93, \mathrm{TLI}=.90, \mathrm{RMSEA}=.11, \mathrm{SRMR}=0.06, \chi^{2}$ difference $=66.29, p$ $<.001$.

Social and Economic Conservatism Scale (Everett, 2013). This 12-item scale assesses both economic ( 5 items) and social ( 7 items) dimensions of conservatism (alphas are reported below because the factor analyses unexpectedly returned a three-factor structure). Participants are asked to indicate how positive or negative they felt about various topics that reflect attitudes towards economic conservatism (e.g., free market, business, welfare state [reversed]) and social conservatism (e.g., traditional marriage, abortion [reversed]), on a scale ranging from 1 (very negative) to 11 (very positive). Since the scale was developed in the 
North American context, we translated the items in French, and replaced some items (e.g., gun ownership, fiscal responsibility) with others more appropriate to the Belgian context (e.g., gay marriage [reversed], religious schools). The need for contextual adaptation was mentioned by the author of the scale. Confirmatory Factor Analysis returned an unsatisfactory fit of the two-factor structure, $\mathrm{CFI}=.62, \mathrm{TLI}=.52, \mathrm{RMSEA}=.16$. On a randomly selected half of the sample, we carried out Principal Components analysis that returned a three-factor structure: social conservatism ("Traditional Value", "Religion", "Patriotism" and "Traditional Marriage", $\alpha=.79$ ), economic conservatism ("Free trade", "Limited government" and "Business", $\alpha=.68$ ), and a third factor which we labeled "hostility against redistribution" (HAR: "Welfare State", "Welfare Subsidies", both reversed, $\alpha=.65)$. We carried out a Confirmatory Factor Analysis on the other half of the sample, which returned an acceptable fit of the model, Chisq/df $=4.51, \mathrm{CFI}=0.93, \mathrm{TLI}=.90$, RMSEA $=.08$, SRMR $=.05$ (detailed analyses are available on the OSF).

The last page consisted of sociodemographic questions: gender, age, political orientation ( 1 = far left, 11 = far right) occupation and nationality. Before completing the questionnaire, participants were able to write an open-ended comment. The first author's email address was provided in case participants had questions about the research.

\section{Results}

Descriptive statistics and correlations are displayed in Table 1. For all of the hierarchical regressions, reversing the order of the blocks of the models did not affect any of the results (see supplementary material on the OSF).

\section{Table 1}

Correlations and Descriptive Statistics (Study 1)

\section{Conspiracy Beliefs and Conservatism}


First, we sought to examine if political conservatism (i.e., the linear term of political orientation) had significantly different relationships with upward (i.e., targeting relatively powerful groups) and downward (i.e., targeting relatively powerless groups) conspiracy beliefs.

Following the method of Judd and colleagues (2017), we computed as a dependent variable a new variable consisting of the difference between belief in upward and downward CTs (see Table 2 for summary of these analyses, Studies 1-3). The rationale is the following: when examining the effect of a predictor (e.g., political conservatism) on this DV, the null hypothesis is that the two types of theories are equally associated to this predictor. Hence, this is an ideal way to examine whether they reflect different social psychological phenomena. Note that this method actually consists of an interaction analysis, as it examines if the relation between the independent variables and conspiracy belief is moderated by the type of conspiracy belief. Thus, we will refer to this method as interaction analysis hereafter.

The regression revealed a significant effect of political conservatism, $B=-0.50, t=-$ 14.44, $p<.001$ (see Table 2, Study 1, Model 1). Hence, congruent with H1, belief in upward and downward CTs relate significantly differently to participants' conservatism, as captured by the left-right scale.

\section{Table 2}

Interaction analyses. Difference between Upward and Downward Conspiracy Beliefs as

\section{Dependent Variable (Studies 1-3)}

We further expected that downward CTs would be associated with a right-wing political orientation, more so than upward CTs. To test this, we carried out hierarchical regression. Political orientation was introduced at Step 1, and the quadratic term was introduced at Step 2 (see next section). Corroborating H2, we found a strong linear relation between belief in downward CTs and political orientation, $B=0.49, t=14.51, p<.001, R^{2}=$ 
.21 (see Table 3), so that right wing participants were more likely to endorse this type of CT. By contrast, we found no linear relationship between belief in upward CTs and political orientation, $B=-.02, t=-0.57, p=.57$.

As expected from $\mathrm{H} 3$, beliefs in upward and downward CTs had significantly different relationships with the social component of conservatism, $B=-0.18, t=-4.26, p<.001$ (see Table 2, Study 1, Model 2). Specifically, belief in downward CTs were more strongly associated with social conservatism, $r=.41,95 \%$ CI $[.35 ; .46], p<.001$, than upward CTs, $r$ $=.14,95 \% \mathrm{CI}[.07 ; .21], p<.001$. The relations were also significantly different for the economic dimension of conservatism, $B=-0.26, t=-6.15, p<.001$. Belief in downward CTs were positively associated with this dimension, $r=.21$, 95\% CI $[.14 ; .27], p<.001$, whereas belief in upward CTs were slightly and negatively correlated, $r=-.12,95 \% \mathrm{CI}[-.06 ;-.19], p$ $<.001$. Finally, belief in upward and downward CTs also had distinct relations with hostility against redistribution, $B=-0.25, t=-7.25, p<.001$, so that belief in downward CTs was more strongly associated with this dimension, $r=.36,95 \%$ CI $[.30 ; .42], p<.001$, than upward CTs, $r=.08,95 \%$ CI $[.01 ; .15], p=.018$. Thus, congruent with $\mathrm{H} 4$ and our results regarding the left-right scale, we found that all dimensions of conservatism were significantly more associated with downward CTs than with upward CTs.

Table 3

Hierarchical Regressions for Belief in Upward and Downward CTs (Study 1)

\section{Conspiracy Beliefs and Political Extremism}

As for political extremism, we expected that upward CTs and downward CTs would have a significantly different relationship with political extremism (i.e., the quadratic term of political orientation). Surprisingly, in the interaction analysis, we found no significant effect of political extremism on the difference between belief in upward and downward CTs, $B=-$ $0.01, t=0.63, p=.52$ (see Table 2, Study 1, Model 1). H5 is therefore not corroborated, and 
we cannot exclude the possibility that upward and downward conspiracy beliefs might both be associated with political extremism.

H6 predicted that belief in upward CTs would be associated with political extremism. In support of the hypothesis, introducing political extremism at Step 2 of the hierarchical regression (after political orientation, see Table 3) revealed that political extremism significantly predicted belief in upward CTs, $B=0.04, t=3.07, p=.002, \Delta R^{2}=.01$, suggesting that participants with an extreme political orientation tended to endorse this type of beliefs more than moderates. Surprisingly, but congruent with the interaction analysis, a positive quadratic effect was also observed for downward CTs, $B=0.05, t=3.94, p<.001$, $\Delta R^{2}=.02$, suggesting the same pattern.

Despite being widely used, testing a U-shaped relationship using quadratic regression has important limitations. Depending on the actual shape of the tested relationship, this method can lead to important rates of false positives or false negatives (Simonsohn, 2018). Hence, to test the robustness of this U-shaped relationship, we carried out the "two lines test" (Simonsohn, 2018) in order to verify if the quadratic regression actually captured the hypothesized U-shaped relationship.

The rationale of the test is to split the distribution in two and carry out two linear regressions, one expected to have negative slope (on the left side of the breakpoint), and the other to have a positive slope (on the right side of the breakpoint, or the other way around for an inverted U-shaped relationship). The test was carried out using an online application created by Simonsohn (http://webstimate.org/twolines/). The Robin Hood Algorithm determined the breakpoint at 3 of the political orientation scale. On the left side of the breakpoint $(n=243)$, we found the expected negative slope, $B=-.78, z=-3.8, p<.001$. On the right side of the breakpoint $(n=543)$, the positive slope was not significant, $B=0.07, z=$ $1.49, p=.14$. Examination of the conditional means scatterplot (see Figure 1a) suggests that 
the positive relationship between political orientation and belief in upward CTs among the right wing is underestimated, for there is an unexpected "bump" around the political orientation median point (i.e., participants self-positioning themselves in the centre of the political orientation scale seemed to endorse slightly more upward CTs than left and right wing moderates). This distribution made the Robin Hood Algorithm inadequate to determine the breakpoint. Based on a suggestion by Simonsohn (personal communication), we used the most extreme cutoff after the "bump" (political orientation $>=8, n=149$ ). This yielded the expected significant positive relationship between political orientation and belief in upward CTs, $B=0.82, t=4.24, p<.001$, so that far right participants endorsed more CTs than right wing moderates. This corroborates the hypothesized U-shaped relationship.

As for belief in downward CTs, the two-lines test did not corroborate the U-shaped relationship (see Figure 1b). Indeed, the Robin Hood Algorithm set the break point at 3 on the political orientation scale. On the left side of the breakpoint $(N=243)$, instead of a negative slope, we found a positive one, $B=0.42, z=8.56, p<.001$. As expected, the right side of the breakpoint also revealed a significant and positive linear effect of political orientation on belief in downward CTs, $B=0.97, z=8.1, p<.001$. 


\section{Figure 1}

Two Lines Test for the Relation between Political Orientation and Conspiracy Beliefs (Study

1)

Figure 1a. Upward Conspiracy Beliefs

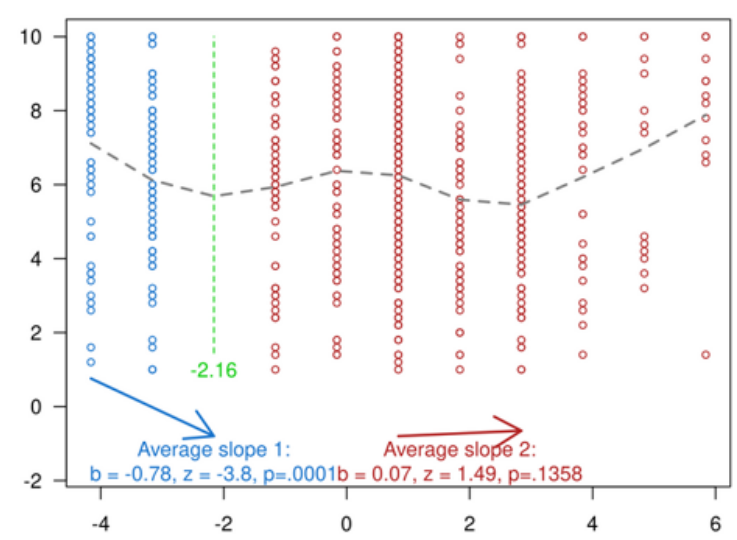

Figure 1b. Downward Conspiracy Beliefs

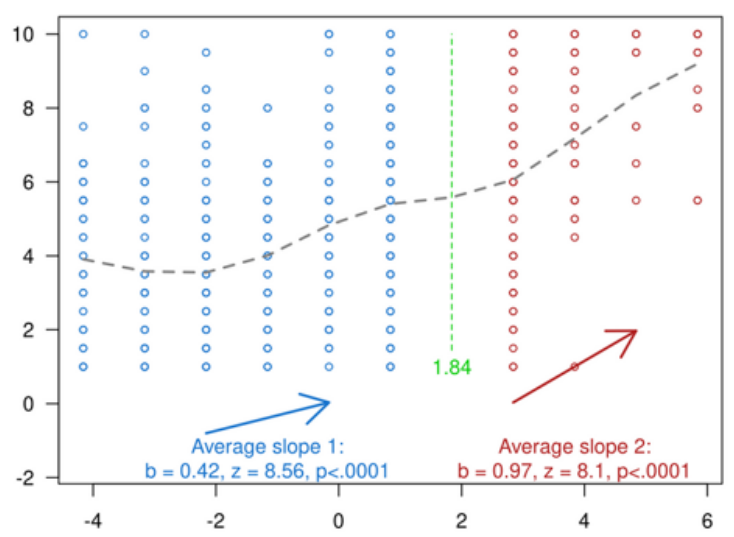

Note. Centered political orientation and conspiracy beliefs are on the $\mathrm{X}$ and $\mathrm{Y}$ axes, respectively.

\section{Discussion}

Even though both types of CTs were correlated, we found that congruent with our hypotheses, belief in downward CTs were significantly more associated with conservatism (measured with both the left-right scale, as well as subcomponents of conservatism) than belief in upward CTs. By contrast, belief in upward CTs had a U-shaped relationship with political orientation, suggesting a relation with political extremism, while it was not the case for downward CTs. Indeed, although belief in upward and downward CTs did not significantly differ in their relation to the quadratic term of political orientation, the two-lines test revealed that only belief in upward CTs had an actual U-shaped relation with political orientation.

Thus, this first study corroborates the idea that belief in upward CTs might be associated with power-challenging attitudes, whereas downward CTs might be more associated with conservative attitudes. We however observed that both types of CTs were robustly correlated, and positively associated with the social component of conservatism. 


\section{Study 2}

A second study was conducted to replicate and extend the results of Study 1. In order to better capture power-challenging attitudes, we added a measure of feelings of leadership breakdown (i.e., the belief that the leadership of society has no legitimacy, Teymoori et al., 2016) to complement the measure of political extremism. Thus, in subsequent studies, conservative attitudes were assessed with the left-right scale and the dimensions of conservatism, and power-challenging attitudes were assessed with political extremism (captured through a U-shaped relationship with political orientation) and leadership breakdown.

We tested the same hypotheses as in Study 1. In addition, we tested whether upward and downward CTs had significantly different relations with our second measure of powerchallenging attitudes, that is, feelings of leadership breakdown (H7). We expected that belief in upward CTs would be positively associated with this variable (H8), more than belief in downward CTs.

Last, we included a validated measure of generic conspiracist beliefs, namely, the single item conspiracy beliefs scale (SICBS, Lantian et al., 2016), to examine associations between general conspiracy beliefs and both upward and downward conspiracy beliefs.

\section{Method}

\section{Participants}

The survey was completed by 912 Belgian residents recruited in January 2019 using a Facebook advertisement targeting Belgian residents. In order to avoid an over-representation of retired people, the advertisement exclusively targeted participants above the age of 18 , and under the age of 60. Seven hundred and seventy-seven participants remained in the sample after excluding those who incorrectly answered the two attention checks and the seriousness check or were under 18 years old (361 women and 416 men). One hundred and sixty-three 
participants were students (21\%), 353 were employees (45.4\%), 63 were self-employed (8.1\%), 73 were unemployed (9.4\%), 33 were retired (4.2\%), and the remaining participants ticked the box "other" $(11.9 \%)$. The mean age was 40.2 years old $(S D=14.6)$, and the mean political orientation was $5.31(S D=2.29)$ from a scale ranging from 1 (far left) to 11 (far right). For a power of .90 , the sample size enabled to detect an effect size of $r=.12$ with two tailed tests.

\section{Procedure and Materials}

Study 2 followed the same procedure as Study 1, except that the questionnaire was slightly longer with the inclusion of the additional variables. The questionnaire included the following scales, in this order: leadership breakdown, dimensions of conservatism, conspiracy beliefs, single item conspiracist beliefs (Lantian et a., 2016), and sociodemographic questions.

Upward $(\alpha=.84)$ and Downward CTs $(r=.38, p<.001)$. We used the same scales as in Study 1. Participants rated their level of agreement with the items on a scale ranging from 1 (completely disagree) to 9 (completely agree). The two factors model returned a satisfactory fit, Chisq/df $=4.55, \mathrm{CFI}=.97, \mathrm{RMSEA}=.07, \mathrm{SRMR}=0.04$. As in Study 1 , the two types of CTs were positively correlated, $r=.34, p<.001$. Contrary to the previous study, a single factor structure returned insufficient fit, Chisq/df $=10.69, \mathrm{CFI}=.92, \mathrm{SRMR}=.06$, RMSEA $=.11$

Leadership Breakdown (Collange et al., 2021, $\alpha=$.94). This scale consists of 10 items measuring the belief that society's leadership is not legitimate and does not pursue the common good nor cares about the most vulnerable (e.g., "The government works towards the welfare of people"; "The political system privileges the protection of vulnerable people"; "the political system is legitimate"; "the political system works as it should", all reversed). The scale was adapted from Teymoori et al. (2016) by Collange et al. (2021) for the French 
context. Participants answered on a 7-point scale from strongly disagree (1) to strongly agree (7).

Adapted Social and Economic Conservatism Scale (Everett, 2013). We removed the items that did not fit in the factor structure in Study 1, and added items to capture the three dimensions that emerged from the factor analysis: economic conservatism ("free market", "limited government”, "business", “diminution of state expenses", “capitalism”, “planned economy" [reversed], "taxes" [reversed], $\alpha=.75$ after removing the reversed items), social conservatism ("religious education", "traditional marriage", "traditional values", "patriotism", "traditional family", $\alpha=.79$ ) and hostility against redistribution ("welfare subsidies", "wealth redistribution", "welfare state", "free healthcare for the most precarious", all reversed, $\alpha=.80$ ). Participants rated how they felt about those concepts on a scale from 1 (very negative) to 9 (very positive). Confirmatory factor analysis revealed that the fit of the model was poor, Chisq $/ \mathrm{df}=8.32, \mathrm{CFI}=.81, \mathrm{TLI}=.78, \mathrm{RMSEA}=.10, \mathrm{SRMR}=$ 0.11. After removing the reversed items "planned economy" and "taxes" from the "economic conservatism" dimension, the fit of the factor structure became acceptable, Chisq $/ \mathrm{df}=4.38$, $\mathrm{CFI}=.93, \mathrm{TLI}=.91, \mathrm{RMSEA}=.07, \mathrm{SRMR}=0.06$

Single Item Conspiracy Beliefs Scale (Lantian et al., 2016). This scale begins with participants reading a short paragraph ("Some political and social events are debated (for example 09/11 attacks, the death of Lady Diana [...]). It is suggested that the "official version" of these events could be an attempt to hide the truth to the public. [...]"). After reading, participants are asked to rate the following statement on a scale ranging from 1 (completely false) to 9 (completely true): "I think that the official version of the events given by the authorities very often hides the truth".

Sociodemographic information: gender, age, occupation, political orientation $(1=$ far left, $11=$ far right), and seriousness check. 


\section{Results}

Descriptive statistics and correlations between variables are displayed in Table 4.

\section{Table 4.}

Descriptive Statistics and Correlations (Study 2)

\section{Conspiracy Beliefs and Conservatism}

As in Study 1, political orientation was a significant predictor of the difference between belief in upward and downward CTs, $B=-.57, t=-17.11, p<.001$ (see Table 2, Study 2, Model 1). In other words, beliefs in upward and downward CTs had significantly distinct relations with the left-right scale.

$\mathrm{H} 2$ was that we would find a linear relationship between belief in downward CTs and political orientation. Congruent with this hypothesis, belief in downward CTs was significantly predicted by a right-wing political orientation, $B=0.51, t=16.36, p<.001, \Delta R^{2}$ $=.26$ (see Table 5). By contrast, we failed to observe a linear relationship between political orientation and belief in upward CTs, $B=-.06, t=-1.89, p=.059, \Delta R^{2}=.004$.

\section{Table 5}

Hierarchical Regression: Political Orientation (Linear and Quadratic) and Belief in CTs (Study 2)

The same pattern of results was observed for the components of conservatism. Belief in downward CTs were (again) significantly more related to the social dimension of conservatism, $B=-0.39, t=-8.15, p<.001$, than belief in upward CTs (see Table 2, Study 2, Model 2). Indeed, belief in downward CTs was robustly correlated with the social component of conservatism, $r=.40,95 \%$ CI $[.34 ; .46], p<.001$, while belief in upward CTs was unrelated to this dimension, $r=-.00,95 \% \mathrm{CI}[-.07 ; .07], p=.97$. Belief in upward and downward CTs also had distinct relation with the economic dimension of conservatism, $B=-$ $0.44, t=-9.42, p<.001$. Belief in downward CTs was positively associated with economic 
conservatism, $r=.19,95 \%$ CI $[.12 ; .26] \mathrm{p}<.001$, while belief in upward CTs was negatively correlated to this dimension, $r=-.29,95 \% \mathrm{CI}[-.36 ;-.22], p<.001$. Finally, both types of conspiracy beliefs had significantly different relationships with hostility against redistribution, $B=-0.20, t=-5.45, p<.001$. Belief in downward CTs was more associated with this dimension, $r=.36,95 \%$ CI $[.30 ; .42], p<.001$, than belief in downward CTs, $r=$ $.19,95 \%$ CI $[.12 ; .26], p<.001$. These results corroborate H3 and H4.

\section{Conspiracy Beliefs and Power-Challenging Attitudes}

As in Study 1, the quadratic term of political orientation was not a significant predictor of the difference between beliefs in upward and downward CTs, $B=-0.01, t=-0.49, p=.62$ (see Table 2, Study 2, Model 1), suggesting that upward and downward conspiracy beliefs do not have a significantly different relation to political extremism. H5 is therefore not corroborated.

H6 was that belief in upward CTs would have a positive U-shaped relationship with political orientation. Step 2 of the hierarchical regression revealed the expected quadratic effect of political orientation, $B=0.03, t=2.25, p=.025, \Delta R^{2}=.006$ (see Table 5). We also found a significant quadratic effect of political orientation for belief in downward CTs, $B=$ $0.03, t=2.81, p=.005$.

As in Study 1, we tested if the quadratic regression captured the hypothesized U-shaped relationship using the "two lines test" (Simonsohn, 2018). The breakpoint was determined at 4 on the political orientation scale (see Figure 2a). The left side of the breakpoint showed the expected negative relationship between political orientation and belief in upward CTs, $B=-$ $0.32, z=-2.58, p=.01$. As for the right side of the breakpoint, we observed no significant positive slope, $B=0.02, z=0.36, p=.72$. However, as in Study 1 , there was an unexpected "bump" at the median point of the political orientation scale, so that participants ticking the central value of the scale endorsed slightly more upward CTs. Using an alternative cutoff 
before the "bump" (political orientation $<=8, N=139$ ), we observed the expected positive relationship between political orientation and upward CTs, $B=0.41, t=2.14, p=.034$, so that far right participants endorsed these beliefs more than moderate right participants. Hence, far right and far left participants endorsed upward CTs more than moderates of the same political wing. This corroborates $\mathrm{H}_{3}$ and replicates results from Study 1.

\section{Figure 2}

Two Lines Test for the Relation between Political Orientation and Conspiracy Beliefs (Study 2)

Figure 2a. Upward Conspiracy Beliefs Figure 2b. Downward Conspiracy Beliefs.
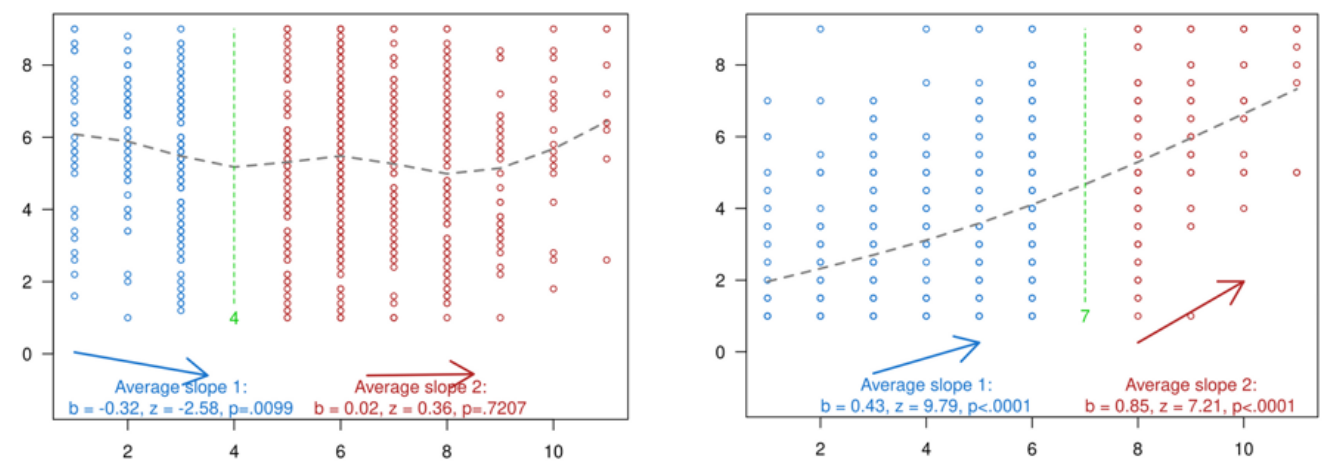

Note. Conspiracy beliefs and political orientation on the $\mathrm{Y}$ and $\mathrm{X}$ axes, respectively.

As for belief in downward CTs, the two lines test revealed that on the left side of the breakpoint (set at 7 on the political orientation scale), the slope was positive, $B=0.43, z=$ $9.79, p<.001$, as it was on the right side of the break point, $B=0.85, z=7.21, p<.001$ (see Figure $2 b$ ). Thus, despite a significant quadratic regression coefficient, there was no Ushaped relationship between political orientation and downward CTs.

Finally, congruent with $\mathrm{H} 7$ and H8, belief in upward CTs were significantly more associated with feelings of leadership breakdown, $r=.56$, 95\% CI $[.51 ; .61], p<.001$, than with belief in downward CTs, $r=.18,95 \%$ CI [.12; .25], $p<.001$ (see Table 2, Study 2, Model 3, for the interaction analysis corroborating H7). 
Additional Analyses. The Single Item Conspiracy Beliefs Scale was a significant predictor of the difference between upward and downward conspiracy beliefs, $B=0.21, t=$ $6.23, p<.001$, suggesting significantly different relations. Specifically, the single item conspiracist beliefs scale was more associated with belief in upward CTs, $r=.67,95 \% \mathrm{CI}$ $[.62 ; .70], p<.001$, than with belief in downward CTs, $r=.35,95 \%$ CI $[.28 ; .41], p<.001$. Finally, a hierarchical regression with the linear and quadratic terms of political orientation as independent variables revealed that the SICBS was not predicted by political orientation, $B=$ $0.01, t=-0.18, p=.85$, nor by political extremism, $B=0.02, t=1.10, p=.27$.

\section{Discussion}

Study 2 replicated and extended results from Study 1. As expected, belief in downward CTs was strongly associated with a conservative ideology, whereas upward conspiracy beliefs were characterized by a U-shaped relationship with political orientation, as well as a strong relationship with feelings of leadership breakdown. Note that downward conspiracy beliefs were also positively associated with feelings of leadership breakdown, though to a much lesser extent. Similarly, upward conspiracy beliefs were more strongly associated with the general conspiracy belief measure than downward conspiracy beliefs.

\section{Study 3}

In Study 3, we attempted to replicate results from Studies 1-2 using a different measure of upward and downward conspiracy beliefs. Indeed, CT inventories have limitations, and notably, the choice and wording of the items can substantially affect the results (Clemm van Hohenberg, 2020). We therefore designed a measure of conspiracy beliefs that would not be influenced by the wording of individual items, nor by the arbitrary choice of the conspiring groups. Moreover, this new measure addresses the issue of the low reliability of the scale measuring downward CTs used in Studies 1-2. 
In this study, we also did not make self-positioning on the left-right scale mandatory. Thus, the analyses involving this variable were carried out only on participants who felt they could position themselves on this scale. The fact that self-positioning on the political orientation scale was mandatory in Studies 1-2 might explain the higher scores of conspiracy beliefs among participants ticking the central value of the scale (i.e., the "bump" found when carrying out the two lines test). Indeed, this value might be ticked by default by participants who reject this measure of political orientation.

\section{Method}

\section{Participants}

The survey was completed by 871 Belgian residents recruited in August 2020 using a Facebook advertisement, out of whom 805 remained after excluding those who did not answer correctly to the attention check, seriousness check, or were under 18 years old (513 males, 286 females, 6 "other”). The mean age was 50 years old $(S D=13.5)$. Seventy-four were students (9.1\%), 354 were employees (44\%), 72 were self-employed (8.9\%), 62 were unemployed (7.7\%), 140 were retired (17.4\%), and the remaining 103 ticked the option "other" (12.9\%). Six hundred and forty-four participants ( $80 \%$ of the sample) positioned themselves on the 9-point left-right political orientation scale $(M=4.60, S D=2.13)$. For a given power of .90 , the sample size enabled us to detect effect sizes of $r=.11$ (for $N=805$ ) and $r=.13(N=644)$.

\section{Procedure and Materials}

Study 3 followed the same procedure as Studies 1-2. Complete scales, analyses files, and pdf version of the questionnaire are all available on the OSF. The order of the scales was randomized, with the exception of sociodemographic variables which were presented on the last page of the questionnaire. Participants completed the following scales: 
Social and Economic Conservatism Scale. We used the same scale as in Study 2, and as in the original study (Everett, 2013), participants positioned themselves on an 11-point feeling thermometer ranging from 0 (very negative) to 100 (very positive). Given that the Confirmatory Factor Analysis returned an insufficient fit, chisq $/ \mathrm{df}=7.5, \mathrm{p}<.001, \mathrm{CFI}=.87$, SRMR $=.06, \mathrm{RMSEA}=.09$, four items were removed ("limited government", "limitation of public expenses (to reduce the public debt)", "catholic religious schools", "religious marriage"). The final dimensions consisted of economic conservatism ("capitalism", "Free market", "business", $\alpha=.71$ ), social conservatism (“traditional values", "patriotism”, "traditional family", $\alpha=.79$ ), and hostility against redistribution ("welfare benefits for the poorest", "welfare state", "wealth redistribution", "free healthcare for the poorest", $\alpha=.82$ ). This solution returned a good fit, chisq $/ \mathrm{df}=5.13, \mathrm{CFI}=.95, \mathrm{SRMR}=.05, \mathrm{RMSEA}=.07$.

Upward and Downward Conspiracy Beliefs. In a pilot study $(N=234$, see online supplements for detailed description of the study), we created a measure of conspiracy beliefs that would not be influenced by the wording of individual items. This measure consisted of an introductory paragraph: "Some groups are suspected of engaging in secret activities for the benefit of their group, to the detriment of the rest of society. These benefits can be economic (e.g., money, settling positions in society) or symbolic (e.g., impose or deconstruct norms or ideas). Please rate the extent to which you consider it likely that the members of the following groups are secretly working against the majority for their own profit."

Participants then rated on a scale ranging from 1 (extremely unlikely) to 7 (extremely likely) five relatively powerful groups (European Union, International Monetary Fund, the government, politicians, the Army), and five relatively powerless groups (Muslims, migrants, Roma, LGBT+ lobbies, feminist lobbies). A third set of groups emerged from an Exploratory Factor Analysis in the pilot study (see online supplements) and was included for exploratory 
analyses. These five groups included foreign powers and tech companies (Saudi government, Russian government, Chinese government, Facebook and Amazon).

Confirmatory Factor Analysis for a three-factor structure did not return a sufficient fit, chisq $/ \mathrm{df}=13.05, p<.001, \mathrm{CFI}=.83, \mathrm{SRMR}=.07, \mathrm{RMSEA}=.12$. An Exploratory Factor Analysis without the Amazon and Facebook items returned a four-factor structure with an acceptable fit, chisq/df $=8.53, \mathrm{p}<.001, \mathrm{CFI}=.91$, SRMR $=.06$, RMSEA $=.10:$ upward CTs, downward "gender" CTs (LGBT+ and feminists, $r=.65, p<.001$ ), downward “immigrants" CTs (Muslims, migrants, and Romas, $\alpha=.82$ ), and foreign governments (Russian government, Chinese government, Saudi Arabia government, $\alpha=.82$ ). Note that conceptually, this fourth factor could be considered as upward CTs. Given that gender and immigrants CTs were substantially correlated, $r=.54,95 \%$ CI $[.49 ; .59], p<.001$, these scales were combined for the confirmatory analyses $(\alpha=.83)$. Correlations between other dimensions ranged from $r=.17,95 \%$ CI $[.10 ; .23], p<.001$ (between gender and foreign government conspiracy beliefs) to $r=.39,95 \%$ CI [.33; .45], $p<.001$ (between "immigrants" and "powerful groups" conspiracy beliefs).

Participants also completed the 10 items of the leadership breakdown scale used in Study $2(\alpha=.93)$. At the end of the questionnaire, participants reported their gender (M/F/Other), age, professional situation, level of education, political orientation, subjective socioeconomic status, and completed the single item conspiracy beliefs scale. The questionnaire ended with the seriousness check.

\section{Results}

Descriptive statistics and correlations are displayed in Table 6.

\section{Table 6}

Descriptive Statistics and Correlations (Study 3)

Conspiracy Beliefs and Conservative Attitudes 
As in the previous studies, we first tested if upward and downward CTs had distinct relation with political orientation. In line with $\mathrm{H} 1$, it was the case, $B=-0.33, t=-10.64, p<$ .001 (see Table 2, Study 3, Model 1). Congruent with our expectations, there was a strong linear relation between political orientation and downward CTs, $B=0.34, t=12.09, p<.001$, $R^{2}=.19$ (see Table 7). Conversely, no linear relationship was found for belief in upward CTs, $B=0.03, t=0.95, p=.34, \Delta R^{2}=.00$.

\section{Table 7}

Hierarchical Regressions on Belief in Upward CTs and Downward CTs (Study 3)

As in Studies 1-2, downward and upward conspiracy beliefs had significantly distinct relationships with social conservatism, $B=-0.11, t=-4.89, p<.001$ (see Table 2, Study 3, Model 2). Belief in downward CTs were more strongly correlated with social conservatism, $r$ $=.35,95 \%$ CI $[.29 ; .41], p<.001$, than belief in upward CTs, $r=.13,95 \%$ CI $[.06 ; .20], p<$ .001. Downward and upward conspiracy beliefs also had significantly distinct relationships with economic conservatism, $B=-0.13, t=-4.71, p<.001$. Specifically, belief in downward CTs were positively correlated with this dimension, $r=.11,95 \%$ CI [.04; .17], $p=.002$, while belief in upward CTs were negatively associated with this dimension, $r$ $=-.16,95 \% \mathrm{CI}[-.09 ;-.23], p<.001$. Finally, both types of conspiracy beliefs had also significantly distinct relations with hostility against redistribution, $B=-0.15, t=-6.61, p<$ .001. Belief in downward CTs was robustly associated with hostility against redistribution, $r$ $=.29,95 \% \mathrm{CI}[.23 ; .35], p<.001$, while belief in upward CTs was unrelated to this dimension, $r=.06,95 \%$ CI [-.01; .13], $p=.07$. These results corroborate H3 and H4.

\section{Conspiracy Beliefs and Power Challenging Attitudes}

As expected, and supporting H5, belief in upward and downward CTs had distinct relation with political extremism, $B=0.03, t=2.14, p=.032$ (see Table 2, Study 3, Model 1). Congruent with H6, the quadratic term of political orientation significantly predicted upward conspiracy beliefs, $B=0.05, t=3.93, p<.001, \Delta R^{2}=.02$ (see Table 7). By contrast, the 
quadratic term of political orientation did not significantly predict downward conspiracy beliefs, $B=0.02, t=1.59, p=.11, \Delta R^{2}=.003$.

For upward conspiracy beliefs, the two lines test set the breakpoint at 4 on the political orientation scale. On the left side of the breakpoint, we observed the expected negative slope, $B=-0.29, \mathrm{z}=-3.1, p=.002$ (see Figure 3a). The right side of the breakpoint was associated with a positive slope, $B=0.16, \mathrm{z}=2.81, p=.005$. This corroborates the $\mathrm{U}$-shaped relationship.

\section{Figure 3}

Two Lines Test for the Relation between Political Orientation and Conspiracy Beliefs (Study

3)

Figure 3a. Upward Conspiracy beliefs

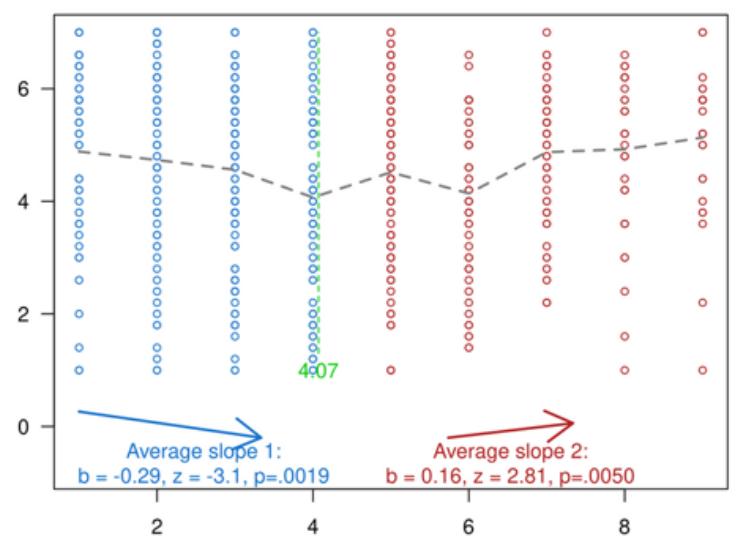

Figure $3 b$. Single item conspiracy beliefs scale

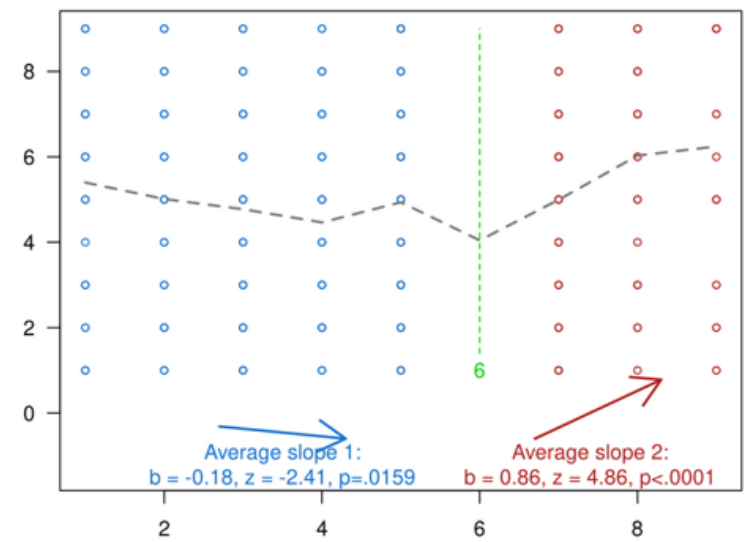

Note. Political orientation and conspiracy beliefs are respectively on the $\mathrm{X}$ and $\mathrm{Y}$ axes.

Last, congruent with $\mathrm{H} 7$ and H8, we found that feelings of leadership breakdown had a significantly stronger relationship with upward conspiracy beliefs, $r=.50,95 \%$ CI $[.45 ; .55]$, $p<.001$, than with downward conspiracy beliefs, $r=.19,95 \%$ CI $[.12 ; .26], p<.001$ (see

Table 2, Study 3, Model 3, for the interaction analysis).

\section{Additional Analyses}

The SICBS significantly predicted the difference between upward and downward conspiracy beliefs, $B=0.08, t=3.29, p=.001$, suggesting different relations. Just like in 
Study 2, the single item conspiracist beliefs scale was significantly more associated with belief in upward CTs, $r=.42,95 \%$ CI $[.37 ; .48], p<.001$, than with belief in downward CTs, $r=.26,95 \% \mathrm{CI}[.19 ; .32], p<.001$. A hierarchical regression with the linear and quadratic terms of political orientation as independent variables revealed that just like upward conspiracy beliefs, the SICBS was not predicted by the linear term of political orientation, $B$ $=0.03, t=0.68, p=.49$, but was predicted by political extremism, $B=0.08, t=4.12, p<$ .001. The two-lines test corroborated a U-shaped relation, with a negative slope on the right side of the breakpoint (set at 6 on the political orientation scale), $B=-0.18, z=-2.41, p=$ .016 , and a positive slope on the right side, $B=0.86, z=4.86, p<.001$ (see Figure $3 \mathrm{~b}$ ).

Last, we examined how conspiracy beliefs targeting powerful foreign governments (Russia, China, Saudi Arabia) were predicted by the linear and quadratic term of political orientation. The linear term of political orientation was not a significant predictor, $B=0.03, t$ $=0.81, p=.42$. Interestingly, the quadratic term was a negative predictor, $B=-0.03, t=-$ $2.64, p=.008$, suggesting an inverted U-shaped relation. The trend, however, was too weak to return significant results with the two lines test. Indeed, the positive slope on the left side of the break point (set at 5 on the political orientation scale) was not significant, $B=0.09, z=$ $1.39, p=.17$, and neither was the negative slope on the right side, $B=-0.11, z=-1.56, p=$ .12 (see Figure 3c). Interestingly, this dimension was not related to the single item conspiracy beliefs scale, $r=.04,95 \%$ CI $[-.03 ; .11], p=.31$.

\section{General Discussion}

In this research, we sought to examine whether belief in CTs targeting relatively powerful groups (upward CTs) and relatively powerless groups (downward CTs) are associated with distinct ideological underpinnings. Following early theorization of the conspiracist mindset, we hypothesized that upward conspiracy beliefs would be associated with power-challenging attitudes (i.e., political extremism and feelings of leadership 
breakdown in our studies), and that downward conspiracy beliefs would be associated with conservative attitudes (i.e., right wing political orientation, and the components of conservatism). Doing so, we sought to add nuance to the claim that conspiracy beliefs are a relatively homogeneous phenomenon that can be captured by a single construct.

Congruent with our expectations, and across all studies, upward conspiracy beliefs were significantly more associated with power-challenging attitudes than downward CTs. Conversely, downward conspiracy beliefs were significantly more associated with conservative attitudes than belief in upward CTs. Upward conspiracy beliefs were characterized by a U-shaped relationship with political orientation and a strong relationship with feelings of leadership breakdown. The latter is not surprising, since many upward CTs directly accuse political groups of conspiring for their own benefit. Thus, as expected, this type of CTs seems to be tightly related to the rejection of power structures.

By contrast, belief in downward CTs was characterized by a strong relationship with a right-wing political orientation, the social dimension of conservatism, and hostility against wealth redistribution. These beliefs were also positively and modestly associated with feelings of leadership breakdown; however, crucially, conservative attitudes were better predictors of the endorsement of these beliefs than power-challenging attitudes or the measure of generic conspiracist beliefs used in Studies 2-3.

Note that our results do not support the idea that downward and upward conspiracy beliefs are entirely distinct phenomena. Across all studies, both types of conspiracy beliefs were positively correlated even though they targeted radically different groups. This is congruent with past research (Wagner-Egger \& Bangerter, 2007) and supports the existence of the construct of a "conspiracist mindset". However, our results corroborate the idea that upward and downward conspiracy beliefs might partly have distinct ideological underpinnings, and bring two nuances to the "single construct" approach to CTs. 
First, our findings question the assumption that generic measures of conspiracy beliefs adequately capture individuals' propensity to believe in any kind of CT. In this regard, we note that in Studies 2-3, the single item conspiracist beliefs scale was a significantly stronger predictor of upward conspiracy beliefs than of downward conspiracy beliefs (a finding that replicates Dyrendal et al., 2018). Since this measure explicitly targets authorities and so called "mainstream" media, it is not surprising that it better captures conspiracy beliefs targeting relatively powerful groups than those related to relatively powerless groups. However, this disproportionate focus on powerful groups (e.g., governments, intelligence services, secret organizations controlling world events, and so on) is common in measures of individual propensity to believe in CTs (e.g., Brotherton et al., 2013; Bruder et al., 2014; Imhoff \& Bruder, 2014). Thus, these measures might not capture individuals' propensity to believe in any $\mathrm{CT}$, but rather, mainly in upward CTs.

Second, and relatedly, our results question the idea that a generalized "conspiracist mindset" can be characterized as a power-challenging ideology. Such a power-challenging approach seems to be relevant to investigate belief in upward CTs, but it seems to be less the case for downward CTs. Thus, if a conspiracist mindset is defined as the individual propensity to believe in any kind of CT, we believe it should not be assumed that such propensity is primarily characterized as power-challenging. It appears that the ideological underpinning of one's endorsement of CTs seems to partly differ depending on the type of groups CTs target.

This research also empirically corroborates the theoretical distinction between the upward and downward trends of research on CTs whose origin can be traced back to, respectively, the conspiracy theory of society analyzed by Popper $(1945 ; 2002)$ and the conspiracy mentality theorized by Moscovici (1987). Indeed, even if CTs implicating relatively powerful groups and those implicating relatively powerless groups are correlated, 
they still seem to be relatively distinct phenomena, underpinned by distinct ideological attitudes. Hence, research on CTs might benefit by explicitly acknowledging the existence of this distinction.

In our view, such acknowledgement is even more necessary given that these two trends of research tend to implicitly endorse slightly different definitions of "conspiracy theory", that might cause misunderstandings. For example, proponents of the "Popperian view" might object that downward CTs are not "real" CTs. Indeed, the idea that relatively powerless groups might be accused of successfully pulling off a large-scale conspiracy without being uncovered might sound somewhat contradictory (Imhoff \& Lamberty, 2020). We argue that the validity of such objection depends on one's definition of conspiracy theory. In this regard, we believe that currently, two types of definitions are mobilized in research on CTs.

On the one hand, if one defines "conspiracy theory" as a belief that groups are colluding in secret to achieve a hidden malevolent goal (e.g., Zonis \& Joseph, 1994), CTs might virtually involve any group that might be suspected of conspiring, regardless of the group's actual power. Ultimately, such a definition encompasses any accusations of conspiracy, in any intergroup context. Such a broad definition follows the view of Moscovici (1987) and is carried on by some contemporary authors (e.g., Bale, 2007; Keeley, 1999; van Prooijen \& van Vugt, 2018).

On the other hand, proponents of the conspiracy theory of society adopt, explicitly or implicitly, a relatively different definition. While the former, broader definition is centered on the idea that an outgroup is conspiring against the ingroup, this definition is centered on the belief that behind significant social events, there is a powerful evil group steering the wheel (Douglas et al., 2019; Imhoff \& Bruder, 2014; Popper, 2002). If one endorses such a definition of a CT, it indeed becomes unlikely that an objectively powerless groups can be the 
target of a CT, because successfully carrying out a conspiracy demands considerable power (e.g., to exert censorship on the "mainstream" media).

In sum, rather than discarding the possibility that relatively powerless groups might be the target of CTs, we argue that it would be better to consider these beliefs as derived from partially distinct conceptualizations of CTs, and acknowledge that CTs are a multifaceted phenomenon. As such, CTs might be motivated by a diversity of ideological attitudes, just as they might fulfill distinct psychological needs (Douglas et al., 2017; Sternisko et al., 2020; Wagner-Egger \& Bangerter, 2007).

Finally, even though they are underpinned by different ideological attitudes, upward and downward CTs might have in common a distorted perception of the target groups' power. Indeed, in downward CTs, relatively powerless groups are endowed with power and willingness to conspire through motivated reasoning (Moscovici, 1987). Similarly, many authors have argued that in CTs (specifically in upward CTs), conspirators are perceived as preternaturally powerful (Bale, 2007; Brotherton, 2012; Popper; 1966). Thus, both upward and downward CTs seem to be associated with a distorted perception of power. Ultimately, it appears that the level of power held by a group is not a necessary precondition for a CT to target it. Rather, endowment with power might be part of the very fabric of a CT.

\section{Limitations and Perspectives}

The first and main limitation is the exploratory nature of most of the reported results. Indeed, this article went through multiple rewritings and deviated from the pre-registered hypotheses based on past reviews as well as changes in theoretical framing. Nonetheless, the stability of the results across the three studies suggests that the relations between political attitudes and the two types of conspiracy theories considered in this paper is robust.

A second limitation is that we did not measure perceived power for the various conspiring groups, but instead chose CTs based on whether the group held power in society. 
Future research could examine if objectively powerful and powerless groups are also perceived as such at the psychological level. If CTs are associated with a distorted perception of power, the articulation between objective and perceived power deserves further, and detailed, investigation.

Regarding this issue, we also note that the exploratory factor analysis in Study 3 suggests that at the psychological level, the multidimensionality of conspiracy beliefs might not be organized solely based on perceived power - as, for example, "gender" conspiracy beliefs and "immigrants" conspiracy beliefs loaded on distinct (yet robustly correlated) factors. A parsimonious (but conceptually less precise) alternative would be that conspiracy beliefs are organized based on prejudice (e.g., groups disliked by conservatives, or by extremists). Note that a factor structure based on prejudice is not incompatible with a factor structure based on power, as individuals holding power-challenging attitudes might be prejudiced against powerful groups, and individuals holding conservative attitudes might be prejudiced against powerless groups.

We must also highlight that the distinction between (power-challenging) upward and (conservative) downward conspiracy beliefs has limitations. Notably, some CTs targeting relatively powerful groups are clearly underpinned by conservative concerns (e.g., CTs about climate change). Moreover, in some intergroup contexts, the power balance between the believer in the $\mathrm{CT}$ and the alleged conspirator might not be clearly asymmetrical. The approach developed in this paper does not have clear predictions regarding such "horizontal" CTs. Similarly, CTs targeting Jewish people seem ambiguous with regard to this distinction, as Jews are stigmatized in many countries but are also high in status.

On more general notes, we can mention the cross-sectional design of the studies, which limits conclusions regarding causality. People may develop ideological beliefs that reflect their conspiracy beliefs, but the reverse may hold as well. Experimental or 
longitudinal studies might allow researchers to draw more robust conclusions regarding causality. A second limitation is the use of a convenience sample recruited using Facebook advertisements. While this approach enables researchers to target a specific audience and to control the validity of the responses using attention and seriousness checks, this may also result in specific biases in the recruitment of participants (Goldberg et al., 2019; Zhang et al., 2018). Examining if our results hold in a more carefully constituted sample (e.g., a nationally representative sample) would surely be a substantial contribution to research. Similarly, examining whether these results replicate in a different national context (i.e., non-French speaking Belgium) would be a valuable contribution.

Last, for our hypotheses regarding belief in upward and downward CTs, we used measures of conspiracy beliefs that were not validated by prior research. This approach is justified by the fact that no existing scale enabled us to clearly make this distinction. Nevertheless, replicating these results after validating a scale tapping into these subdimensions of CTs might enable us to draw more robust conclusions.

\section{Conclusion}

In this research, we provided evidence that belief in CTs implicating relatively powerful groups and relatively powerless groups are positively correlated but have distinct relationships with power-challenging and conservative attitudes, and with a generic measure of conspiracy beliefs. These differential relations highlight the existence of diverging trends of research on CTs, which assume different mechanisms of endorsement as well as different definitions of CTs. We believe that being (self-)conscious about the diverging trends of research on CTs, as well as the diverging conceptualizations of CTs and the notion of conspiracy mindset, might help clarify and refine one's understanding of CTs, avoid overgeneralizations in future research, and reflect about how distorted power perception might play a role in the yet-to-be clearly conceptualized, "conspiracist mindset". 


\section{Conflict of interest and ethics statement}

None of the authors have any conflicts of interest to declare. The five authors confirm that this article adheres to ethical guidelines specified in the APA Code of Conduct as well as the national ethics guidelines of Belgium.

\section{Data transparency statement}

All materials, data, and analyses reported in this article are openly available on the Open Science Framework at https://osf.io/utvf3/ 


\section{References}

Abalakina-Paap, M., Stephan, W. G., Craig, T., \& Gregory, W. L. (1999). Beliefs in Conspiracies. Political Psychology, 20(3), 637-647. doi:10.1111/0162-895x.00160

Amy, D.J. (2000). Behind the Ballot Box: A citizen's Guide to Voting Systems. London: Praeger.

Bale, J. M. (2007). Political paranoia vs political realism: on distinguishing between bogus conspiracy theories and genuine conspiratorial politics. Patterns of Prejudice, 41(1), 45-60.

Bauer, P. C., Barbera, P., Ackermann, K., \& Venetz, A. (2017). Is the Left-Right Scale a Valid Measure of Ideology? Individual-Level Variation in Associations with "Left" and "Right" and Left-Right Self-Placement. Political Behavior, 39(3), 553-583. doi:10.1007/s11109-016$9368-2$

Bilewicz, M., Winiewski, M., Kofta, M., \& Wójcik, A. (2013). Harmful Ideas, The Structure and Consequences of Anti-Semitic Beliefs in Poland. Political Psychology, 34(6), 821-839. doi:10.1111/pops. 12024

Brotherton, R. (2013). Towards a definition of "conspiracy theory". PsyPAG Quarterly, 88(3), 914.

Brotherton, R., French, C. C., \& Pickering, A. D. (2013). Measuring Belief in Conspiracy Theories: The Generic Conspiracist Beliefs Scale. Frontiers in Psychology, 4, 279. doi:10.3389/fpsyg.2013.00279

Bruder, M., Haffke, P., Neave, N., Nouripanah, N., \& Imhoff, R. (2013). Measuring Individual Differences in Generic Beliefs in Conspiracy Theories across Cultures: Conspiracy Mentality Questionnaire. Frontiers in Psychology, 4, 225. doi:10.3389/fpsyg.2013.00279

Campion-Vincent, V. (2005). From Evil Others to Evil Elites A Dominant Pattern in Conspiracy Theories Today. In Campion-Vincent, V. (Ed.). Rumor Mills: The Social Impact of Rumor and Legend. New York: Routledge. 
Clemm von Hohenberg, B. (2020, July 30). Truth and Bias: Biased Findings. https://doi.org/10.31219/osf.io/yj2rn

Crocker, J., Luhtanen, R., Broadnax, S., \& Blaine, B. E. (1999). Belief in U.S. Government Conspiracies Against Blacks among Black and White College Students: Powerlessness or System Blame? Personality and Social Psychology Bulletin, 25(8), 941-953. doi:10.1177/01461672992511003

De Jonge, L. (2020). The Curious Case of Belgium: Why is There no Right-Wing Populism in Wallonia? Government and Opposition, 1-17. doi:10.1017/gov.2020.8

Dieguez, S., Wagner-Egger, P., \& Gauvrit, N. (2015). "Nothing happens by accident”, or does it? A low prior for randomness does not explain belief in conspiracy theories. Psychological Science, 26, 1762-1770.

Douglas, K. M., Sutton, R. M., Callan, M. J., Dawtry, R. J., \& Harvey, A. J. (2016). Someone is pulling the strings: Hypersensitive agency detection and belief in conspiracy theories. Thinking \& Reasoning, 22(1), 57-77. doi : 10.1080/13546783.2015.1051586

Douglas, K. M., Sutton, R. M., \& Cichocka, A. (2017). The Psychology of Conspiracy Theories. Current Directions in Psychological Science, 26(6), 538-542. doi: $\underline{10.1177 / 0963721417718261}$

Douglas, K. M., Uscinski, J. E., Sutton, R. M., Cichocka, A., Nefes, T., Ang, C. S., \& Deravi, F. (2019). Understanding Conspiracy Theories. Political Psychology, 40(S1), 3-35. doi:10.1111/pops. 12568

Dyrendal, A., Kennair, L.E.O. \& Lewis, J.R. (2018). The Role of Conspiracy Mentality and Paranormal Beliefs in Predicting Conspiracy Beliefs Among Neopagans. International Journal for the Study of New Religions, 8(1), 73-97. https://doi.org/10.1558/ijsnr.36716 Everett, J. A. C. (2013). The 12 items Social and Economic Conservatism Scale (SECS). PloS One, 8(12), e82131. doi:10.1371/journal.pone.0082131 
Featherstone, J. D., Bell, R. A., \& Ruiz, J. B. (2019). Relationship of people's sources of health information and political ideology with acceptance of conspiratorial beliefs about vaccines. Vaccine, 37(23), 2993-2997. doi:10.1016/j.vaccine.2019.04.063

European Union Agency for Fundamental Rights (2012). Enquête LGBT dans l'UE : Enquête sur les personnes lesbiennes, gays, bisexuelles et transgenres dans l'Union européenne: les résultats en bref. Retrieved from: https://fra.europa.eu/sites/default/files/eu-lgbt-surveyresults-at-a-glance_fr.pdf

Freeman, D., \& Bentall, R. P. (2017). The concomitants of conspiracy concerns. Social Psychiatry and Psychiatric Epidemiology, 52(5), 595-604. doi:10.1007/s00127-017-1354-4

Galliford, N., \& Furnham, A. (2017). Individual difference factors and beliefs in medical and political conspiracy theories. Scandinavian Journal of Psychology, 58, 422-428. doi:10.1111/sjop.12382.

Goertzel, T. (1994). Belief in Conspiracy Theories. Political Psychology, 15(4), 731-742. $\underline{\text { doi: } 10.2307 / 3791630}$

Goldberg, M., van der Linden, S., Ballew, M. T., Rosenthal, S. A., \& Leiserowitz, A. (2019, August 23). Convenient but biased? The reliability of convenience samples in research about attitudes toward climate change. doi:10.31219/osf.io/2h7as

Greszniak-Feldman, M., \& Irzycka, M. (2009). Right-Wing Authoritarianism and Conspiracy Thinking in a Polish Sample. Psychological Reports, 105(2), 389-393. doi:10.2466/PR0.105.2.389-393

Harambam, J., \& Aupers, S. (2016). "I Am Not a Conspiracy Theorist": Relational Identifications in the Dutch Conspiracy Milieu. Cultural Sociology, 11(1), 113-129. doi: $\underline{10.1177 / 1749975516661959}$

Hart, J., \& Graether, M. (2018). Something's going on here: Psychological predictors of belief in conspiracy theories. Journal of Individual Differences, 39, 229-237. doi:10. 
$1027 \% 2 \mathrm{f} 1614-0001 \% 2 \mathrm{fa} 000268$.

Hornsey, M. J., Harris, E. A., \& Fielding, K. S. (2018). Relationships among conspiratorial beliefs, conservatism and climate scepticism across nations. Nature Climate Change, 8(7), 614- 620. doi: 10.1038/s41558-018-0157-2

Imhoff, R., \& Bruder, M. (2014). Speaking (Un-) Truth to Power: Conspiracy Mentality as a Generalised Political Attitude. European Journal of Personality, 28(1), 25-43. doi:0.1002/per.1930

Imhoff, R., Dieterle, L., \& Lamberty, P. (2020). Resolving the Puzzle of Conspiracy Worldview and Political Activism: Belief in Secret Plots Decreases Normative but Increases Nonnormative Political Engagement. Social Psychological and Personality Science, 194855061989649. doi:10.1177/1948550619896491

Imhoff, R., \& Lamberty, P. (2020). Conspiracies as psycho-political reactions to power. In Butter, M., \& Knight, P. (Eds.). Routledge Handbook of Conspiracy Theories (pp. 192-206). Abingdon-on-Thames: Routledge.

Imhoff, R., Zimmer, F., Klein, O., António, J.H.C., Babinska, M., Bangerter, A., Bilewicz, M., Blanuša, N., Bovan, K., Bužarovska, R., Cichocka, A., Delouvée, S., Douglas, K.M., Dyrendal, A., Gjoneska, B., Graf, S., Gualda, E., Hirschberger, G., Kende, A., ..., \& van Prooijen, J.W. (under review). Conspiracy mentality and political orientation across 26 countries. Judd, C. M., McClelland, G. H., Ryan, C. S., McClelland, G. H., \& Ryan, C. S. (2017). Data Analysis: A Model Comparison Approach To Regression, ANOVA, and Beyond, Third Edition. New York: Routledge

Johnson, S. D., \& Tamney, J. B. (2001). Social Traditionalism and Economic Conservatism: Two Conservative Political Ideologies in the United States. The Journal of Social Psychology, 141(2), 233-243. doi:10.1080/00224540109600549 
Jolley, D., Meleady, R., \& Douglas, K. M. (2019). Exposure to intergroup conspiracy theories promotes prejudice which spreads across groups. British Journal of Psychology ; 111(1), 1735. doi:10.1111/bjop.12385

Jolley, D., \& Paterson, J. L. (2020). Pylons ablaze: Examining the role of 5G COVID-19 conspiracy beliefs and support for violence. British Journal of Social Psychology, 59(3), 628640. doi:10.1111/bjso.12394

Kofta, M., \& Sedek, G. (2005). Conspiracy Stereotypes of Jews during Systemic Transformation in Poland. International Journal of Sociology, 35(1), 40-64. doi:10.2466/pr0.102.3.755-758

Krouwel, A., Kutiyski, Y., van Prooijen, J.-W., Martinsson, J., \& Markstedt, E. (2017). Does extreme political ideology predict conspiracy beliefs, economic evaluations and political trust? Evidence from Sweden. Journal of Social and Political Psychology, 5(2), 435-462. doi:10.23668/psycharchives. 1839

Lantian, A., Muller, D., Nurra, C., \& Douglas, K. M. (2016). Measuring Belief in Conspiracy Theories: Validation of a French and English Single-Item Scale. International Review of Social Psychology, 29(1). doi:10.5334/irsp.8

Lukić, P., Žeželj, I., \& Stanković, B. (2019). How (Ir)rational Is it to Believe in Contradictory Conspiracy Theories? Europe's Journal of Psychology, 15(1), 94-107. https://doi.org/10.5964/ejop.v15i1.1690

Magee, J. C., \& Galinsky, A. D. (2008). The self-reinforcing nature of power and status. Academy of Management annals, 2, 351-398.

Marchlewska, M., Cichocka, A., Łozowski, F., Górska, P., \& Winiewski, M. (2019). In search of an imaginary enemy: Catholic collective narcissism and the endorsement of gender conspiracy beliefs. The Journal of Social Psychology, 159(6), 766-779. doi: $10.1080 / 00224545.2019 .1586637$ 
Mendelssohn, A.D. (2015). The Rag Race: How Jews Sewed Their Way to Success in America and the British Empire. New York: New York University Press.

Miller, J. M., Saunders, K. L., \& Farhart, C. E. (2016). Conspiracy Endorsement as Motivated Reasoning: The Moderating Roles of Political Knowledge and Trust. American Journal of Political Science, 60(4), 824-844. doi:10.1111/ajps.12234

Moscovici, S. (1987). The Conspiracy Mentality. In Graumann, C.F., \& Moscovici, S. (1987). Changing Conceptions of Conspiracy (pp. 151-169). New York: Springer.

Muller, J.Z. (2011). Capitalism and the Jews. Princeton: Princeton University Press

Newman, B. J., Hartman, T. K., \& Taber, C. S. (2012). Foreign Language Exposure, Cultural Threat, and Opposition to Immigration. Political Psychology, 33(5), 635-657. doi:10.1111/j.1467-9221.2012.00904.x

Oliver, J. E., \& Wood, T. J. (2014). Conspiracy Theories and the Paranoid Style(s) of Mass Opinion. American Journal of Political Science, 58(4), 952-966. doi:10.1111/ajps.12084

Pasek, J., Stark, T. H., Krosnick, J. A., \& Tompson, T. (2015). What motivates a conspiracy theory? Birther beliefs, partisanship, liberal-conservative ideology, and anti-Black attitudes. Electoral Studies, 40, 482-489. doi:10.1016/j.electstud.2014.09.009

Popper, K. (1945). The open society and its enemies. Vol. II: The High Tide of Prophecy: Hegel, Marx, and the Aftermath. New York: Routledge.

Popper, K. (2002). Conjectures and Refutations : The Growth of Scientific Knowledge. New York: Routledge.

Richey, S. (2017). A Birther and a Truther: The Influence of the Authoritarian Personality on Conspiracy Beliefs. Politics \& Policy, 45(3), 465-485. doi:10.1111/polp.12206 Rosseel, Y., Jorgensen, T. D., Oberski, D., Byrnes, J., Vanbrabant, L., Savalei, V., ... Scharf, F. (2019). lavaan: Latent Variable Analysis (Version 0.6-5). Retrieved from https://CRAN.Rproject.org/package=lavaan 
RTBF (2019, May 27). Au Parlement wallon, le PS s'érode, mais reste premier devant le MR et Ecolo. $R T B F$. Retrieved from: https://www.rtbf.be/info/election/circonscription/detail_lesresultats-des-elections-regionales-wallonnes-2019?id=10216045

Simonsohn, U. (2018). Two Lines: A Valid Alternative to the Invalid Testing of U-Shaped Relationships With Quadratic Regressions. Advances in Methods and Practices in Psychological Science, 1(4), 538-555. doi:10.1177/2515245918805755

Ståhl, T., \& van Prooijen, J.-W. (2018). Epistemic rationality: Skepticism toward unfounded beliefs requires sufficient cognitive ability and motivation to be rational. Personality and Individual Differences, 122, 155-163. doi:10.1016/j.paid.2017.10.026

Sternisko, A., Cichocka, A., \& Van Bavel, J. J. (2020). The dark side of social movements: Social identity, non-conformity, and the lure of conspiracy theories. Current opinion in psychology, 35, 1-6.. doi: 10.1016/j.copsyc.2020.02.007

Sutton, R., \& Douglas, K. (2014). Examining the monological nature of conspiracy theories. In van Prooijen, J.W., \& van Lange, P.A.M. (Eds). Power, Politics, and Paranoia: Why People are Suspicious of their Leaders (pp. 252-272). Cambridge University Press. doi:10.1017/CBO9781139565417.018

Sutton, R. M., \& Douglas, K. M. (2020). Conspiracy theories and the conspiracy mindset: Implications for political ideology. Current Opinion in Behavioral Sciences, 34, 118-122. doi: $10.1016 /$ j.cobeha.2020.02.015

Swami, V., Barron, D., Weis, L., \& Furnham, A. (2017). To Brexit or not to Brexit: The roles of Islamophobia, conspiracist beliefs, and integrated threat in voting intentions for the United Kingdom European Union membership referendum. British Journal of Psychology, 109(1), 156-179. doi:10.1111/bjop.12252

Swami, V., Barron, D., Weis, L., Voracek, M., Stieger, S., \& Furnham, A. (2017). An Examination of the Factorial and Convergent Validity of Four Measures of Conspiracist 
Ideation, with Recommendations for Researchers. PloS One, 12(2), e0172617. doi:10.1371/journal.pone.0172617

Swami, V., Coles, R., Stieger, S., Pietschnig, J., Furnham, A., Rehim, S., \& Voracek, M. (2011). Conspiracist Ideation in Britain and Austria: Evidence of a Monological Belief System and Associations between Individual Psychological Differences and Real-World and Fictitious Conspiracy Theories. British Journal of Psychology, 102(3), 443-463. doi:10.1111/j.2044$\underline{8295.2010 .02004 . x}$

Teymoori, A., Jetten, J., Bastian, B., Ariyanto, A., Autin, F., Ayub, N., ... Wohl, M. (2016). Revisiting the Measurement of Anomie. PLOS ONE, 11(7), e0158370. doi:10.1371/journal.pone. 0158370

Uenal, F. (2016). The Secret Islamization of Europe Exploring the Integrated Threat Theory: Predicting Islamophobic Conspiracy Stereotypes. International Journal of Conflict and Violence, 10(1), 93-108. doi:10.4119/UNIBI/ijcv.499

Unia (2019). Marché du travail et origine : monitoring socioéconomique. Retrieved from: https://emploi.belgique.be/sites/default/files/content/publications/FR/MonitoringSocioecono mique2019.pdf

Uscinski, J. E., Douglas, K., \& Lewandowsky, S. (2017). Climate Change Conspiracy Theories. Oxford Research Encyclopedia of Climate Science. doi:10.1093/acrefore/9780190228620.013.328

Uscinski, J. E., Klofstadt, C., \& Atkinson, M. D. (2016). What Drives Conspiratorial Beliefs? The Role of Informational Cues and Predispositions. Political Research Quarterly, 69(1), 57-71. $\underline{\text { doi: } 10.1177 / 1065912915621621}$

Uscinski, J. E., \& Parent, J. M. (2014). American Conspiracy Theories. Oxford University Press. 
van der Linden, S. (2015). The conspiracy-effect: Exposure to conspiracy theories (about global warming) decreases pro-social behavior and science acceptance. Personality and Individual Differences, 87, 171-173. doi:10.1016/j.paid.2015.07.045

van der Linden, S., Panagopoulos, C., Azevedo, F., \& Jost, J. T. (2020). The Paranoid Style in American Politics Revisited: An Ideological Asymmetry in Conspiratorial Thinking. Political Psychology. doi :10.1111/pops.12681

Van Prooijen, J.-W. (2016). Why Education Predicts Decreased Belief in Conspiracy Theories. Applied Cognitive Psychology, 31(1), 50-58. doi:10.1002/acp.3301 van Prooijen, J.-W (2018). The Psychology of Conspiracy Theories. New York: Routledge doi:10.4324/9781315525419

van Prooijen, J.-W. (2020). An existential threat model of conspiracy theories. European Psychologist, 25(1), 16-25. https://doi.org/10.1027/1016-9040/a000381

van Prooijen, J.-W., Krouwel, A. P., \& Pollet, T. V. (2015). Political Extremism Predicts Belief in Conspiracy Theories. Social Psychological and Personality Science, 6(5), 570-578. doi:10.1177/1948550614567356

van Prooijen, J.-W., Staman, J., \& Krouwel, A. P. M. (2018). Increased conspiracy beliefs among ethnic and Muslim minorities. Applied Cognitive Psychology, 32(5). 661-667 doi:10.1002/acp.3442

Van Prooijen, J.-W., \& van Vugt, M. (2018). Conspiracy Theories: Evolved Functions and Psychological Mechanisms. Perspectives on Psychological Science, 174569161877427. doi:10.1177/1745691618774270

Wagner-Egger, P., \& Bangerter, A. (2007). La Vérite Est Ailleurs: Corrélats de l'adhésion Aux Théories Du Complot. Revue Internationale de Psychologie Sociale, 20(4), 31-61. Retrieved from: https://www.cairn.info/revue-internationale-de-psychologie-sociale-2007-4-page$\underline{31 . h t m}$ 
Wood, M. J., Douglas, K. M., \& Sutton, R. M. (2012). Dead and Alive: Beliefs in Contradictory Conspiracy Theories. Social Psychological and Personality Science, 3(6), 767-773. doi: $10.1177 / 1948550611434786$

Zhang, B., Mildenberger, M., Howe, P. D., Marlon, J., Rosenthal, S. A., \& Leiserowitz, A. (2018). Quota sampling using Facebook advertisements. Political Science Research and Methods, 17. doi: $\underline{10.1017 / p s r m .2018 .49}$

Zonis, M., \& Joseph, C. M. (1994). Conspiracy Thinking in the Middle East. Political Psychology, 15(3), 443-459. https://doi.org/10.2307/3791566 


\section{Table 1}

Correlations and Descriptive Statistics (Study 1)

\begin{tabular}{|c|c|c|c|c|c|c|c|c|}
\hline & Mean $(S D)$ & 1 & 2 & 3 & 4 & 5 & 6 & 7 \\
\hline 1. Upward CTs & $5.70(2.29)$ & - & & & & & & \\
\hline 2. Downward CTs & $4.97(2.56)$ & $43^{* *}$ & - & & & & & \\
\hline 3. Political orientation & $5.17(2.43)$ & -.02 & $.46 * *$ & - & & & & \\
\hline 4. Economic conservatism & $5.90(2.30)$ & $-.12 * *$ & $.21 * *$ & $.43 * *$ & - & & & \\
\hline 5. Social conservatism & $6.44(2.26)$ & $.14^{* *}$ & $.41 * *$ & $.41 * *$ & $.44^{* *}$ & - & & \\
\hline 6. HAR & $4.93(2.51)$ & $.08^{*}$ & $.30 * *$ & $.40 * *$ & $.09^{\prime}$ & .07 & - & \\
\hline 7. Age & $54.7(15.6)$ & $.12 * *$ & $.30 * *$ & .02 & $.17 * *$ & $.09^{\prime}$ & $.18 * *$ & - \\
\hline
\end{tabular}

Note. HAR stands for Hostility Against Redistribution.

$* p<.05 * * p<.01$

\section{Table 2}

Difference between Upward and Downward Conspiracy Beliefs as Dependent Variable

(Studies 1-3)

\begin{tabular}{|c|c|c|c|c|c|c|c|c|c|}
\hline \multirow{3}{*}{ Independent variables } & \multicolumn{9}{|c|}{ Dependent variables } \\
\hline & \multicolumn{3}{|c|}{ Interaction term (Study 1) } & \multicolumn{3}{|c|}{ Interaction term (Study 2) } & \multicolumn{3}{|c|}{ Interaction term (Study 3) } \\
\hline & $B$ & $95 \%$ CI & $R^{2}$ & $B$ & $95 \% \mathrm{CI}$ & $R^{2}$ & $B$ & $95 \% \mathrm{CI}$ & $R^{2}$ \\
\hline Model 1: political orientation & & & .21 & & & .28 & & & .15 \\
\hline Intercept & $1.18^{* *}$ & {$[0.96,1.40]$} & & $4.62 * *$ & {$[4.23,5.02]$} & & $2.64 * *$ & {$[2.34,2.95]$} & \\
\hline Political orientation (linear) & $-0.50 * *$ & {$[-0.57,-0.44]$} & & $-0.57 * *$ & {$[-0.64,-0.51]$} & & $-0.33 * *$ & {$[-0.39,-0.27]$} & \\
\hline Political orientation (quadratic) & -0.01 & {$[-0.03,0.02]$} & & -0.01 & {$[-0.03,0.02]$} & & $0.03 *$ & {$[0.00,0.05]$} & \\
\hline Model 2: conservatism & & & .17 & & & .26 & & & .13 \\
\hline Intercept & 5.05 & {$[4.41,5.68]$} & & $6.20 * *$ & {$[5.61,6.79]$} & & $3.39 * *$ & {$[3.00,3.78]$} & \\
\hline Social conservatism & $-0.18 * *$ & {$[-0.26,-0.10]$} & & $-0.39 * *$ & {$[-0.48,-0.29]$} & & $-0.11 * *$ & {$[-0.16,-0.07]$} & \\
\hline Economic conservatism & $-0.26 * *$ & {$[-0.34,-0.17]$} & & $-0.44 * *$ & {$[-0.53,-0.35]$} & & $-0.13 * *$ & {$[-0.18,-0.07]$} & \\
\hline HAR & $-0.25 * *$ & {$[-0.32,-0.18]$} & & $-0.20 * *$ & {$[-0.27,-0.13]$} & & $-0.15 * *$ & {$[-0.19,-0.11]$} & \\
\hline Model 3: Leadership breakdown & & & & & & .08 & & & .06 \\
\hline Intercept & & & & -2.24 & {$[-3.15,-1.33]$} & & -0.35 & {$[-0.81,0.11]$} & \\
\hline Leadership Breakdown & - & - & & $0.53 * *$ & {$[0.40,0.65]$} & & $0.32 * *$ & {$[0.23,0.40]$} & \\
\hline
\end{tabular}

Note. HAR stands for Hostility Against Redistribution.

$* p<.05 * * p<.01$ 


\section{Table 3}

Hierarchical Regressions for Belief in Upward and Downward CTs (Study 1)

\begin{tabular}{|c|c|c|c|c|c|c|c|c|}
\hline \multirow{3}{*}{ Independent variables } & \multicolumn{8}{|c|}{ Dependent variables } \\
\hline & \multicolumn{4}{|c|}{ Upward conspiracy beliefs $\left(\mathrm{H}_{3}\right)$} & \multicolumn{4}{|c|}{ Downward conspiracy beliefs $\left(\mathrm{H}_{4}\right)$} \\
\hline & $B$ & $95 \% \mathrm{CI}$ & $R^{2}$ & $\Delta R^{2}$ & $B$ & $95 \% \mathrm{CI}$ & $R^{2}$ & $\Delta R^{2}$ \\
\hline Step 1 & & & .00 & & & & .21 & \\
\hline Intercept & $6.09 * *$ & {$[5.92,6.26]$} & & & $4.96 * *$ & {$[4.80,5.12]$} & & \\
\hline Political orientation (linear) & -0.02 & {$[-0.09,0.05]$} & & & $0.49 * *$ & {$[0.42,0.55]$} & & \\
\hline Step 2 & & & .01 & .01 & & & .23 & .02 \\
\hline Intercept & $5.86 * *$ & {$[5.64,6.09]$} & & & $4.68 * *$ & {$[4.47,4.89]$} & & \\
\hline Political orientation (linear) & -0.03 & {$[-0.10,0.04]$} & & & $0.47 * *$ & {$[0.41,0.54]$} & & \\
\hline Political orientation (quadratic) & $0.04 * *$ & {$[0.01,0.06]$} & & & $0.05 * *$ & {$[0.02,0.07]$} & & \\
\hline
\end{tabular}

$* p<.05 * * p<.01$

\section{Table 4}

Descriptive Statistics and Correlations (Study 2)

\begin{tabular}{|c|c|c|c|c|c|c|c|c|c|c|}
\hline & Mean $(S D)$ & 1 & 2 & 3 & 4 & 5 & 6 & 7 & 10 & 11 \\
\hline 1. Upward conspiracy beliefs & $5.42(2.02)$ & - & & & & & & & & \\
\hline 2. Downward conspiracy beliefs & $3.87(2.32)$ & $.34 * *$ & - & & & & & & & \\
\hline 3. SICBS & $5.57(2.59)$ & $.67 * *$ & $.35^{* *}$ & - & & & & & & \\
\hline 4. Political orientation & $5.32(2.29)$ & -.07 & $.51^{* *}$ & -.01 & - & & & & & \\
\hline 5. Economic conservatism & $4.34(1.78)$ & $-.29 * *$ & $.19^{* *}$ & $-.19 * *$ & $.48 * *$ & - & & & & \\
\hline 6. Social conservatism & $4.81(1.69)$ & -.00 & $.40 * *$ & -.00 & $.35 * *$ & $.35^{* *}$ & - & & & \\
\hline 7. HAR & $4.87(1.78)$ & $.19 * *$ & $.36 * *$ & $.31 * *$ & $.43 * *$ & .04 & .02 & - & & \\
\hline 10. Leadership breakdown & $7.21(1.36)$ & $.56 * *$ & $.18^{* *}$ & $.50 * *$ & $-.15^{* *}$ & $-.42 * *$ & $-.11 * *$ & $.13^{* *}$ & - & \\
\hline 11. Age & $39.97(14.74)$ & $.16^{* *}$ & $.18 * *$ & $.16^{* *}$ & .00 & $-.13 * *$ & -.05 & $.24 * *$ & $.15 * *$ & - \\
\hline
\end{tabular}

Note. HAR stands for Hostility Against Redistribution.

$* p<.05 * * p<.01$ 


\section{Table 5}

Hierarchical Regression: Political Orientation (Linear and Quadratic) and Belief in CTs

(Study 2)

\begin{tabular}{|c|c|c|c|c|c|c|c|c|}
\hline \multirow{3}{*}{ Independent variables } & \multicolumn{8}{|c|}{ Dependent variables } \\
\hline & \multicolumn{4}{|c|}{ Upward conspiracy beliefs $\left(\mathrm{H}_{3}\right)$} & \multicolumn{4}{|c|}{ Downward conspiracy beliefs $\left(\mathrm{H}_{4}\right)$} \\
\hline & $B$ & $95 \% \mathrm{CI}$ & $R^{2}$ & $\Delta R^{2}$ & $B$ & $95 \% \mathrm{CI}$ & $R^{2}$ & $\Delta R^{2}$ \\
\hline Step 1 & & & .01 & & & & .26 & \\
\hline Intercept & $5.74 * *$ & {$[5.38,6.10]$} & & & $1.14 * *$ & {$[0.79,1.50]$} & & \\
\hline Political orientation (linear) & -0.06 & {$[-0.12,0.00]$} & & & $0.51 * *$ & {$[0.45,0.57]$} & & \\
\hline Step 2 & & & .01 & .01 & & & .26 & .01 \\
\hline Intercept & $5.62 * *$ & {$[5.25,6.00]$} & & & $1.00 * *$ & {$[0.63,1.37]$} & & \\
\hline Political orientation (linear) & $-0.06^{*}$ & {$[-0.13,-0.00]$} & & & $0.51 * *$ & {$[0.45,0.57]$} & & \\
\hline Political orientation (quadratic) & $0.03 *$ & {$[0.00,0.05]$} & & & $0.03 * *$ & {$[0.01,0.05]$} & & \\
\hline
\end{tabular}

$* p<.05 * * p<.01$

Table 6

Descriptive Statistics and Correlations (Study 3)

\begin{tabular}{|c|c|c|c|c|c|c|c|c|c|c|c|c|}
\hline & Mean (SD) & 1 & 2 & 3 & 4 & 5 & 6 & 7 & 8 & 9 & 10 & 11 \\
\hline 1. Upward conspiracy beliefs & $4.74(1.53)$ & - & & & & & & & & & & \\
\hline 2. Downward conspiracy beliefs & $3.41(1.71)$ & $.41^{* *}$ & - & & & & & & & & & \\
\hline 3. Gender conspiracy beliefs & $3.23(1.95)$ & $.32 * *$ & $.82 * *$ & - & & & & & & & & \\
\hline 4. Immigrants conspiracy beliefs & $3.53(1.93)$ & $.39 * *$ & $.92 * *$ & $.54 * *$ & - & & & & & & & \\
\hline 5. Foreign gov. conspiracy beliefs & $5.02(1.70)$ & $.34 * *$ & $.31 * *$ & $.17 * *$ & $.35^{* *}$ & - & & & & & & \\
\hline 6. SICBS & $5.16(2.62)$ & $.42^{* *}$ & $.26^{* *}$ & $.17 * *$ & $.27 * *$ & .04 & - & & & & & \\
\hline 7. Economic conservatism & $5.31(2.35)$ & $-.16 * *$ & $.11 * *$ & $.12 * *$ & $.08 *$ & .01 & $-.13 * *$ & - & & & & \\
\hline 8. Social conservatism & $6.53(2.71)$ & $.13 * *$ & $.35 * *$ & $.31 * *$ & $.31^{* *}$ & $.09 *$ & $.20 * *$ & $.36 * *$ & - & & & \\
\hline 9. HAR & $4.36(2.59)$ & .06 & $.29 * *$ & $.20 * *$ & $.30 * *$ & $-.08 *$ & $.12 * *$ & $.07 *$ & -.04 & - & & \\
\hline 10. Leadership breakdown & $5.25(1.40)$ & $.50 * *$ & $.19^{* *}$ & $.13^{* *}$ & $.19 * *$ & $.07 *$ & $.42 * *$ & $-.36 * *$ & -.01 & $.08 *$ & - & \\
\hline 11. Age & $50(13.5)$ & .06 & $.14 * *$ & .03 & $.19 * *$ & .03 & $.15^{* *}$ & $-.18 * *$ & -.03 & $.09 *$ & $.11 * *$ & - \\
\hline
\end{tabular}

Note. HAR stands for Hostility Against Redistribution.

$* p<.05 * * p<.01$ 
Table 7

Hierarchical Regressions on Belief in Upward CTs and Downward CTs (Study 3)

\begin{tabular}{|c|c|c|c|c|c|c|c|c|}
\hline \multirow{3}{*}{ Independent variables } & \multicolumn{8}{|c|}{ Dependent variables } \\
\hline & \multicolumn{4}{|c|}{ Upward conspiracy beliefs $\left(\mathrm{H}_{3}\right)$} & \multicolumn{4}{|c|}{ Downward conspiracy beliefs $\left(\mathrm{H}_{4}\right)$} \\
\hline & $B$ & $95 \% \mathrm{CI}$ & $R^{2}$ & $\Delta R^{2}$ & $B$ & $95 \% \mathrm{CI}$ & $R^{2}$ & $\Delta R^{2}$ \\
\hline Step 1 & & & .00 & & & & .19 & \\
\hline Intercept & $4.44^{* * *}$ & {$[4.16,4.73]$} & & & $1.74 * *$ & {$[1.45,2.02]$} & & \\
\hline Political orientation (linear) & 0.03 & {$[-0.03,0.08]$} & & & $0.34 * *$ & {$[0.29,0.40]$} & & \\
\hline Step 2 & & & .03 & .03 & & & .19 & .00 \\
\hline Intercept & 4.34 & {$[4.05,4.62]$} & & & $1.69 * *$ & {$[1.40,1.98]$} & & \\
\hline Political orientation (linear) & 0.00 & {$[-0.05,0.06]$} & & & $0.33 * *$ & {$[0.28,0.39]$} & & \\
\hline Political orientation (quadratic) & $0.16^{* *}$ & {$[0.02,0.07]$} & & & 0.02 & {$[-0.00,0.04]$} & & \\
\hline
\end{tabular}

$* p<.05 * * p<.01$ 